\title{
On the Bulk-Skin Temperature Difference and Its Impact on Satellite Remote Sensing of Sea Surface Temperature
}

\author{
Peter Schluessel, ${ }^{1}$ William J. Emery, ${ }^{2}$ Hartmut Grassl, ${ }^{3}$ and Theodor Mammen ${ }^{4}$
}

\begin{abstract}
Satellite infrared sensors only observe the temperature of the skin of the ocean rather than the bulk sea surface temperature (SST) traditionally measured from ships and buoys. In order to examine the differences and similarities between skin and bulk temperatures, radiometric measurements of skin temperature were made in the North Atlantic Ocean from a research vessel along with coincident measurements of subsurface bulk temperatures, radiative fluxes, and meteorological variables. Over the entire 6-week data set the bulk-skin temperature differences $(\Delta \mathrm{T})$ range between -1.0 and $1.0 \mathrm{~K}$ with mean differences of 0.1 to $0.2 \mathrm{~K}$ depending on wind and surface heat flux conditions. The bulk-skin temperature difference varied between day and night (mean differences 0.11 and $0.30 \mathrm{~K}$, respectively) as well as with different cloud conditions, which can mask the horizontal variability of SST in regions of weak horizontal temperature gradients. A coherency analysis reveals strong correlations between skin and bulk temperatures at longer length scales in regions with relatively weak horizontal temperature gradients. The skin-bulk temperature difference is parameterized in terms of heat and momentum fluxes (or their related variables) with a resulting accuracy of $0.11 \mathrm{~K}$ and $0.17 \mathrm{~K}$ for night and daytime. A recommendation is made to calibrate satellite derived SST's during night with buoy measurements and the additional aid of meteorological variables to properly handle $\Delta \mathrm{T}$ variations.
\end{abstract}

\section{INTRODUCTION}

One of the most useful oceanographic applications of operational weather satellite data is the mapping of sea surface temperature (SST) from infrared imagery. While it is widely accepted that satellite infrared sensors measure radiation from only the surface skin of the ocean, most oceanographers are interested in SST more representative of the upper meters of the ocean, commonly referred to as the bulk SST. This interest in the bulk SST has led to a practice of calibrating satellite derived SST's with in situ bulk SST's measured by freely drifting ocean buoys. The difference between skin and bulk temperatures contributes an added level of uncertainty to the satellite retrieved SST calibrated in this manner.

The existence of a cool skin at the top of the ocean was first postulated by Bruck [1940] and Woodcock [1941] and was later verified by observations [Ewing and McAlister, 1960; Saunders, 1967; Clauss et al., 1970; Katsaros, 1977; Grassl and Hinzpeter, 1975; Grassl, 1976]. This cool skin is gencrally several tenths of a degree colder than the temperatures measured just a few centimeters below the surface. While the thickness of this skin

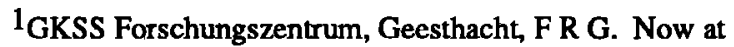
University of Hamburg, Hamburg, F R G.

${ }^{2}$ Colorado Center for Astrodynamics Research, University of Colorado, Boulder.

${ }^{3}$ Max-Planck-Institut fuer Meteorologie, Hamburg, F R G.

${ }^{4}$ Institut fuer Meereskunde, Kiel, F R G.

Copyright 1990 by the American Geophysical Union.
}

Paper number $90 \mathrm{JC} 00515$.

0148-0227/90/90JC-00515\$05.00 layer is always less than a millimeter [Grassl, 1976], its actual thickness depends on the local energy flux through the sea surface due to molecular transports. The sharp temperature gradient, characteristic of the molecular sublayer, persists at wind speeds up to $10 \mathrm{~m} / \mathrm{s}$ [Clauss et al., 1970], above which the skin layer is destroyed by breaking waves. Studies have shown, however, that this skin layer reestablishes itself within 10 to $12 \mathrm{~s}$ [Ewing and McAlister, 1960; Clauss et al., 1970] after the cessation of the destructive influence.

The persistent existence of the skin layer has been explained by theoretical [Hinzpeter, 1967, 1968] and empirical [Sounders, 1967; Hasse, 1971] models which demonstrate that the surface skin layer is needed to resist and regulate the fluxes of longwave radiative energy as well as the sensible and latent turbulent energy fluxes across the sea surface. It is the conductive surface skin layer that effects the molecular exchange of both the radiative and turbulent energy fluxes across the air-sea interface. While above and below this thin skin, turbulent eddy exchange mechanisms carry the heat away from the interface into the ocean and/or atmosphere, these eddy transports cannot carry the heat across the ocean's surface (except by spray bubbles), which is instead accomplished by molecular processes within the skin layer. Thus the existence of the ocean's skin layer has been both observed and explained by various theoretical and empirical studies. In this paper we will use observations to further explore the character of the skin layer, its relationship to external heat fluxes, and its relationship to coincident measurements of bulk temperatures.

Both the thickness and the temperature gradient of the ocean's skin layer are determined by the same heat exchange processes. The skin temperature responds most rapidly to the generally upward directed net longwave irradiance. Since water has high emissivity at the infrared [Friedmann, 1969; Downing and Williams, 1975], the longwave radiation is emitted from (or absorbed by) the upper few micrometers of the ocean, thus 
cooling (or warming) the skin layer. It is these infrared frequencies that are presently used for the remote sensing of SST. Concurrently, the transfer of latent and sensible heat from the ocean to the atmosphere (or vice versa) leads to further, often dominant, cooling at the sea surface. The magnitude of these turbulent fluxes depends on the air-sea temperature and water vapor mixing ratio differences as well as on the surface wind speed creating the turbulent exchanges of heat and momentum. In general the latent heat flux is greater than either the sensible or the longwave radiative fluxes. Nevertheless, as a turbulent flux it does not directly penetrate the ocean's surface, but the heat is exchanged across the skin layer by molecular processes. Only solar insolation is able to penetrate the ocean's surface and transfer heat into the ocean below the skin layer. Depending on the amount of suspended material in the near-surface layer the solar radiation may be absorbed within the upper few decimeters (highly turbid coastal waters) or extend down to decameters in the clearer waters of the open ocean.

During the day, solar heating warms the upper meter of the ocean, creating under low wind conditions, an afternoon temperature maximum (Figure $1 a$ ) a few millimeters below the surface [Grassl, 1977]. Below this shallow temperature maximum is the diumal transition to the lower temperatures of the ocean's mixed layer [Price et al., 1987] while above it the temperature drops from the shallow maximum to create the cool skin of the ocean. At night this maximum is erased by vertical mixing, creating the typical nighttime profile as shown in Figure $1 b$. This profile exhibits the cooler skin layer which is maintained at night by the longwave and turbulent fluxes. These diagrams are intended only to display some very simple cases that generally occur. The great variety of atmospheric and oceanic conditions that actually take place may produce near-surface temperature profiles that do not exactly fit either of these cases. In any event the thin skin of the ocean persists as a feature.

Differences $(\Delta T)$ between the bulk temperature measured more than a meter below the surface and the surface skin temperature range from -1.0 to $1.0 \mathrm{~K}$ [Robinson, 1985]. While this temperature difference appears to be quite small, it is significant in its contribution to infrared satellite SST's for studies of the global climate. At present most satellite SST retrieval methods fail to recognize the importance of the difference between skin and bulk temperature. The most common method of correcting or calibrating satellite SST's is to use bulk temperatures measured from drifting buoys [McClain, 1981; McClain et al., 1985; McClain, 1989] which typically have their sensors mounted between 0.5 and $1.0 \mathrm{~m}$ below the surface. This depth varies as the buoy bounces in the turbulent environment of the sea surface. Root-mean-square differences between buoy and satellite SST
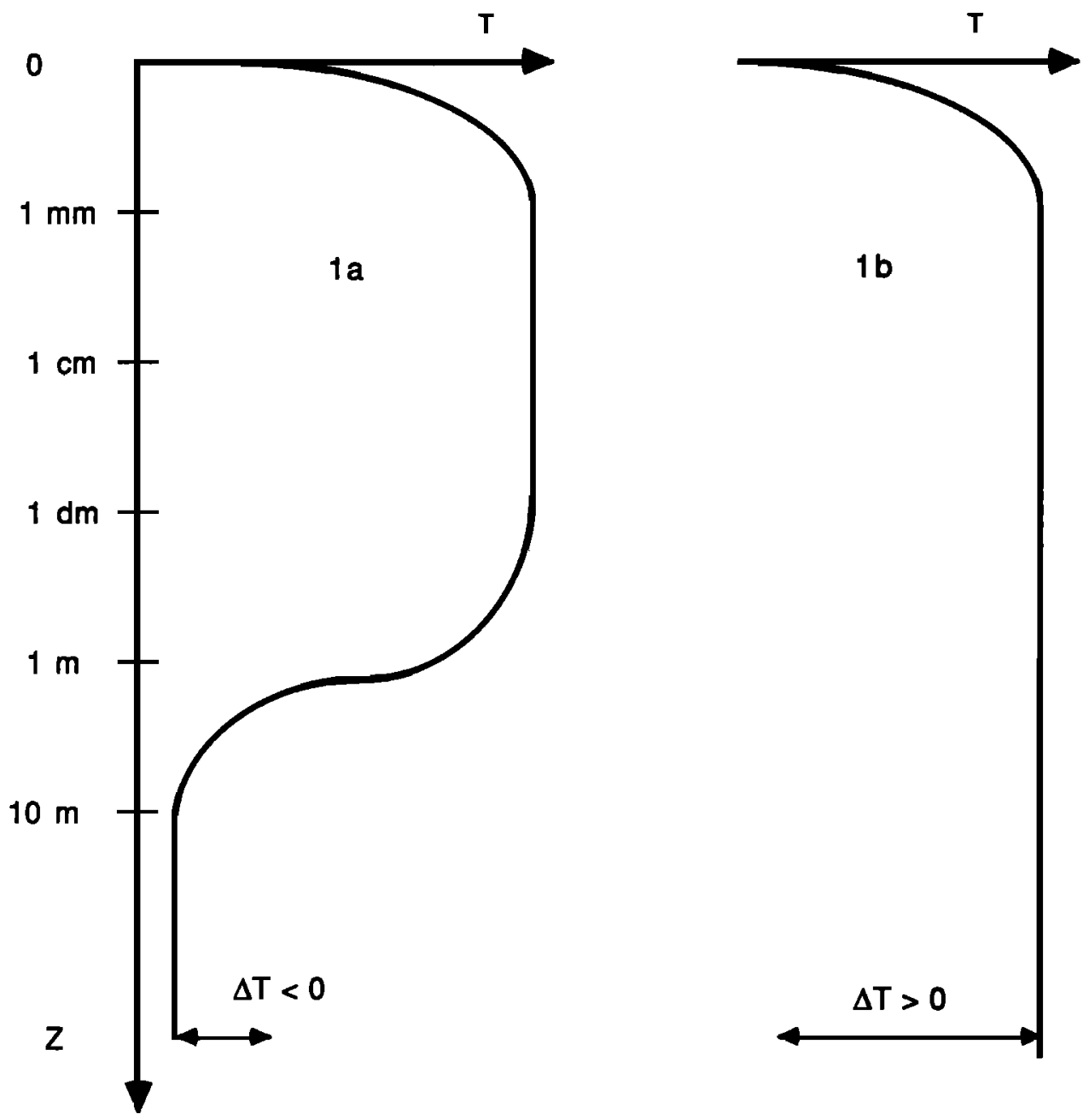

Fig 1. Schematic representation of possible near surface temperature profiles. (a) Day profile with diumal thermocline. (b) Night profile. 
range from 0.5 to $1.5 \mathrm{~K}$ [McClain et al., 1985]. These differences can be attributed to uncompensated atmospheric variability, noise in the radiometric satellite measurements, errors in the buoy data, and the differences between skin and bulk temperatures. Skin temperature estimates [Schluessel et al., 1987] from the satellite are still subject to atmospheric contamination and noise in the measurements but do not require correction for the bulk-skin temperature difference If we are ever to develop satellite remote sensing techniques to attain the $0.2 \mathrm{~K}$ SST accuracy required for climate studies [Robinson et al., 1984], we must account for the bulk-skin temperature difference in the calibration of the satellite infrared data. Once correctly calibrated as surface skin temperature, we can then investigate the relationship between satellite sensed skin temperature and the ocean bulk SST to determine the suite of transforms needed to relate these fundamentally different measures of SST.

\section{THE EXPERIMENTAL SETUP}

From October 20 to November 28, 1984 measurements were taken from the German research vessel Meteor to study the effects of the surface heat fluxes on the skin temperature of the ocean. The geographic study region was the northeast Atlantic from $21^{\circ}$ to $50^{\circ} \mathrm{N}$, between $0^{\circ} \mathrm{E}$ and $28^{\circ} \mathrm{W}$ (Figure 2). Ocean skin temperatures were measured with a Bames PRT-5 radiation thermometer looking over the ship's side at an angle of about $53^{\circ}$ to the vertical (approximately the Brewster's angle to minimize the contribution by the reflected sky radiation); the PRT-5 was equipped with an 9.5-11.5 $\mu \mathrm{m}$ bandpass filter. From a position $11 \mathrm{~m}$ above the sea the radiometer viewed a $0.7 \mathrm{~m}^{2}$ area in front of the breaking waves generated and reflected by the ship. This radiation thermometer

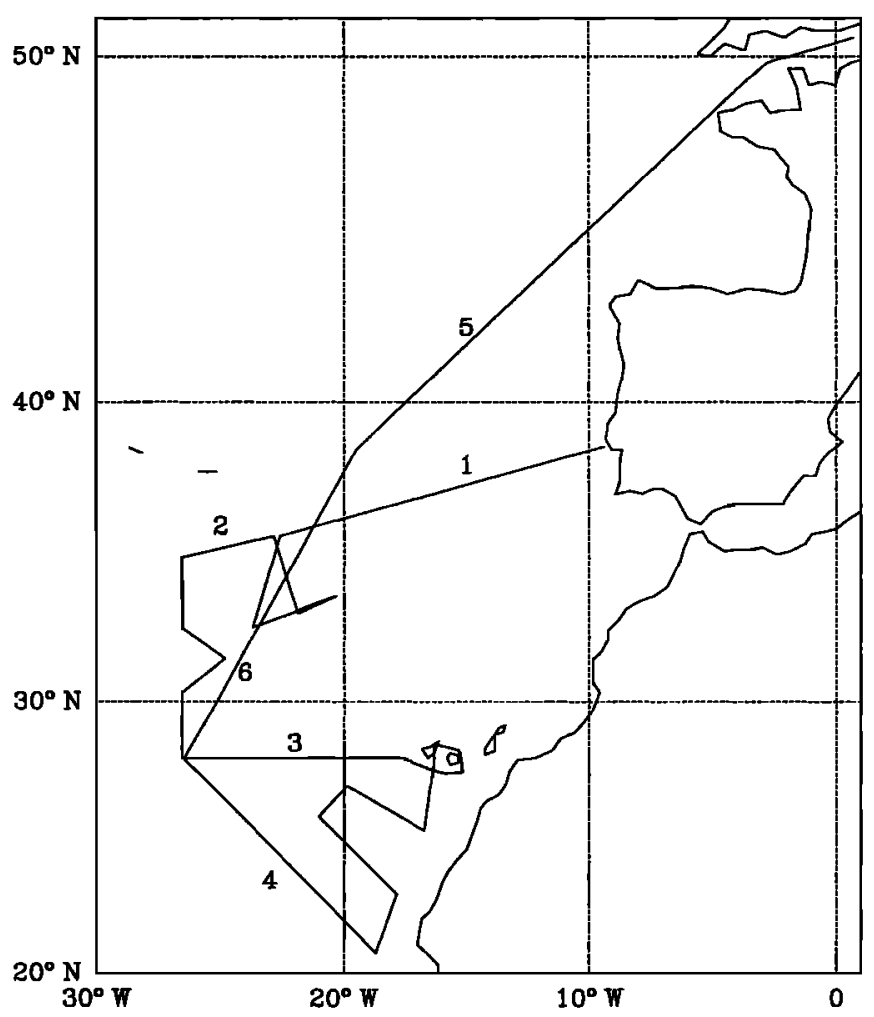

Fig. 2. Experiment area with cruise track; numbers refer to segments described in Table 5. was calibrated every other minute by a well-stirred bucket of sea water which moved in and out of the view of the radiometer. The temperature of the water in this bucket was constantly monitored, providing a PRT-5 calibration accurate to $0.05 \mathrm{~K}$.

Simultaneous measurements were also made of subsurface temperatures using platinum resistance thermometers, calibrated to an absolute accuracy of $0.0125 \mathrm{~K}$ and located at depths of $0.1,2,4$, and $7 \mathrm{~m}$. The temperatures at $0.1 \mathrm{~m}$ were measured only while the ship was stopped on station or was moving very slowly; thus there are far fewer measurements than for the deeper levels. The thermometer at $2 \mathrm{~m}$ was attached to the hull near the bow of the ship, while the $4 \mathrm{~m}$ sample was taken at a sea water intake near the ship's keel. Both were locations where no warm exhaust water could influence the measurements. The $7 \mathrm{~m}$ thermometer was extended $1.5 \mathrm{~m}$ below the ship's hull on a pole. Response times to temperature changes showed values of about $10 \mathrm{~s}$. Analog voltage measurements were converted to frequency shifts and averaged over intervals of a minute. The sampling frequencies ranged from 100 to $500 \mathrm{~Hz}$.

Also continuously measured as 1 -min means were the downwelling longwave irradiance (with an Eppley Pyrgeometer) and the incoming solar irradiance (with a Kipp und Zonen Pyranometer). Together these measurements provided data to compute the radiative heat balance (accurate to about $10 \mathrm{~W} / \mathrm{m} 2$ ). Other meteorological variables measured to compute the turbulent fluxes of sensible and latent heat were the air and wet bulb temperatures (calibrated to give $0.0125 \mathrm{~K}$ accuracy over $1-\mathrm{min}$ intervals apart from ship effects), wind speed and direction as well as ship's speed and direction (5-min means of data accurate to 0.1 $\mathrm{m} / \mathrm{s}$ and $5^{\circ}$ ), and cloud cover (hourly observer estimates). All these measurements were taken at $20 \mathrm{~m}$ above sea level. Also measured each hour were sea level pressure $(0.01 \mathrm{kPa}$ accuracy) and sea state (observer estimate). This suite of measurements allows one to make a thorough study of the surface thermodynamics and the influence they have on the skin temperature and its difference with the subsurface bulk SST. Collected over the entire length of the cruise, these data cover a wide range of meteorological conditions that occurred in the northeast Atlantic.

\section{Calibration of THE RAdiATION Thermometer}

Grassl and Hinzpeter [1975] described the many possible influences on radiative measurements of SST that complicate the calibration of a radiation thermometer operating from a ship. In response they developed a continuous calibration system that was used in this experiment. The system provides calibration information to compensate for the following effects: (1) the deviation of the sea surface emissivity from unity, including the variations of surface reflectivity at viewing angles other than nadir, (2) contributions to the PRT-5 measurements due to reflected radiation from clear sky and clouds, (3) contamination of the entrance optics by sea spray, (4) the temperature drift of the internal reference blackbody, and (5) the drift of the instrument electronics.

The latter two drifts include changes in the instrument due to solar heating of the entire instrument package. These drifts result in changing offsets in the calibration curve relating counts to brightness temperatures. The continuous calibration of the PRT-5 was accomplished by alternating the view between the ocean's surface and the reference reservoir. After a measurement cycle of $1 \mathrm{~min}$ the reference bath was moved into the view of the PRT-5, and a $1 \mathrm{~min}$ sample was taken of the calibration source including nearly the same reflected radiation as seen during the cycle 
before. This reference bath was constantly renewed with sea water from the bottom, which caused strong upwelling in the bucket and guaranteed the continuous destruction of the surface skin layer in the reference tub. The constant vertical motion in the bucket also prevented the formation of temperature gradients in the bath.

The temperature of the reference bath, being the same as the ocean temperature, within a few tenths of a kelvin, was continuously monitored with a platinum resistance thermometer having an accuracy of $0.0125 \mathrm{~K}$. The relationship between reference temperature and radiometer counts was linear for all of the $2 \times 10$ calibration measurements taken during the cruise (not shown here). The slope of this linear relationship was determined by regression between temperature and counts, while the offset for the actual measurement was taken from the mean of two subsequent calibration cycles. This also compensated for changes in the radiation reflected from moving fields of scattered clouds during calibration and measurement cycles. Calibrated in this way, the final accuracy of the skin temperature measurements was $0.05 \mathrm{~K}$; without this rather complicated calibration procedure the radiometric temperatures might deviate by several degrees from the true skin temperatures owing to the effects listed above.

\section{Data Processing}

Laboratory calibrations on all of the sensors except the PRT-5 were performed before and after the experiment. No changes of calibration constants were encountered. Using these calibrations, all erroneous data caused by the ship's radio traffic (received by the data logger) and by the ship's funnel plume were edited out. Errors caused by radio traffic were easily detected, since totally unrealistic measurements were produced. The impact of the warm exhaust plume on the mast measurements (radiation sensors, wet and dry bulb thermometers) was checked using the wind velocity relative to the ship. The mast was placed approximately $10 \mathrm{~m}$ in front of the funnel. All mast data (i.e. air temperature, wet bulb temperature, as well as longwave and downwelling shortwave irradiances) were rejected for wind directions between $150^{\circ}$ and $210^{\circ}$ relative to the ship. Further error checks were performed by editing out all physically unreasonable data. An intercomparison of water temperatures at the lower three levels led to the rejection of temperatures that were more than $0.25 \mathrm{~K}$ away from the mean of these temperatures. All parameters were checked for temporal coherency within five sampling intervals. A measurement spike was eliminated if it deviated by more than a given limit from the mean of the adjacent four samples taken before and after the current sample. The limits used were $2 \mathrm{~K}$ for the skin temperature; $1 \mathrm{~K}$ for the water temperature at $-0.1 \mathrm{~m} ; 0.5 \mathrm{~K}$ for the water temperatures at $-2,-4$ and $-7 \mathrm{~m} ; 1.5 \mathrm{~K}$ for air and wet bulb temperatures; $50 \mathrm{~W} / \mathrm{m}^{2}$ for the longwave downwelling irradiance; $500 \mathrm{~W} / \mathrm{m}^{2}$ for the shortwave downwelling irradiance; $10 \mathrm{~m} / \mathrm{s}$ for the wind speed; $45^{\circ}$ for the wind direction; and $0.7 \mathrm{~K}$ for the bucket temperature (this test was performed before the actual calibration of the PRT-5). About 3.3\% of the total data set for each parameter was rejected by this filtering procedure.

\section{Dependence of $\Delta T$ on Heat FluXES aNd Wind StrfsS}

Following Saunders [1967], the bulk-skin temperature difference should depend on both surface heat fluxes and the kinematic stress on the surface. In order to compute the heat flux we have to parameterize the shortwave albedo and the longwave emissivity of the surface as well as the turbulent fluxes. Also required is a parameterization of the wind stress on the surface from the given measurements. We use the bulk parameterizations for the turbulent fluxes as follows:

Wind stress

$$
\tau=C_{D} \rho u^{2}
$$

Sensible heat

$$
H=C_{H} \rho c_{p} u\left(\theta-T_{s}\right)
$$

Latent heat

$$
E=C_{L} \rho L u\left(q_{a}-q_{s}\right)
$$

where $C_{D}$ is the drag coefficient, $C_{H}$ and $C_{L}$ are the heat flux and evaporation coefficients, $\rho$ is the air density, $u$ is the mean wind velocity, $q_{a}$ and $q_{s}$ are water vapor mixing ratios of sea surface and in the atmosphere, $c_{p}$ is the specific heat of air at constant pressure, $L$ is the latent heat of evaporation, and $T_{s}$ and $\theta$ represent the surface temperature and the overlying potential air temperature. The potential air temperature, atmospheric water vapor mixing ratio, and wind speed are defined as those values measured at $20 \mathrm{~m}$ above the sea surface where they were observed. Unfortunately, there are no coefficients $\mathbf{C}_{\mathbf{H}}$ and $\mathbf{C}_{\mathbf{L}}$ available for use with skin temperatures. The empirical formulae were developed using bulk or "bucket" surface temperatures. Hence, we use the water temperatures measured at $2 \mathrm{~m}$ in equations (2) and (3) (the latter for the calculation of $\mathrm{q}_{s}$ ), and we adopt the coefficients given by Smith [1988] which depend on actual wind speed and vertical stability. All measured quantities have been averaged over hourly intervals before computing the fluxes and wind stress to minimize the effects of noise occurring from short periodic fluctuations of air temperature, humidity, and wind speed $20 \mathrm{~m}$ above the surface that do not generally translate into flux fluctuations through the surface.

The net longwave radiative flux $L$ was computed using the pyrgeometer measurements of the downwelling irradiance together with the PRT-5 measurements of the skin temperature.

$$
\mathbf{L}=\mathbf{L}_{\mathrm{D}}+\mathbf{L}_{\mathbf{u}}
$$

Computation of the downwelling $\left(\mathrm{L}_{\mathrm{D}}\right)$ and upwelling $\left(\mathrm{L}_{\mathrm{u}}\right)$ terms requires knowledge of the reflective properties of the sea surface. The spectral emissivity $\varepsilon_{\lambda}$ of the ocean's surface varies sharply between 3 and $200 \mu \mathrm{m}$ depending on the complex index of refraction for sea water [Downing and Williams, 1975]. Values of $\varepsilon_{\lambda}$ reach from $75 \%$ near $100 \mu \mathrm{m}$ to $95 \%$ near $11 \mu \mathrm{m}$.

The spectrally integrated emissivity $\varepsilon$ is given by the integral over all spectral emissivities weighted by the Planck's function of the surface temperature divided by the total blackbody radiation at the surface temperature:

$$
\varepsilon=\frac{\int_{0}^{\infty} \varepsilon_{\lambda} B_{\lambda}\left(T_{S}\right) d \lambda}{\int_{0}^{\infty} B_{\lambda}\left(T_{S}\right) d \lambda}=\frac{\int_{\lambda}^{\infty} \varepsilon_{\lambda} B_{\lambda}\left(T_{S}\right) d \lambda}{\sigma T_{S}^{4}}
$$

where $\varepsilon$, emissivity; $\lambda$, wavelength; $B$. Planck's function; $T_{S}$, surface temperature; and $\sigma$, Stefan-Boltzmann constant.

During our experiment, surface temperatures varied between 280 and $300 \mathrm{~K}$, leading to spectrally averaged emissivities (E) 
between 88.6 and $89.1 \%$. Thus the net longwave flux is parameterized as

$$
L=\varepsilon L_{D}-\varepsilon \sigma T_{s}^{4}
$$

Computation of the net shortwave flux $S$ requires a knowledge of the oceanic albedo if the shortwave upwelling irradiance is not measured. We used tabulated values of the albedo (a) given by Payne [1972] which allow for corrections for sun elevation, atmospheric turbidity, and surface roughness. The tabulated values require as input the downwelling irradiance $S_{D}$, sun elevation, and wind speed which were extracted or computed from our measurements. The net solar radiative flux can then be written as

$$
S=(1-a) S_{D}
$$

The total heat flux $Q$ through the air-sea interface is the sum of the single contributions, which we write as

$$
\mathbf{Q}=\mathbf{S}+\mathrm{L}+\mathrm{H}+\mathrm{E}
$$

All fluxes have been calculated for hourly averaged measurements. We have neglected the latent heat flux due to precipitation in our calculation owing to a lack of direct observations. All fluxes are defined here as positive when directed into the ocean.

\section{TIME SERIES}

An exemplary insight into the roles of these heat exchange terms can be gained by examining individual time series selected from the entire data set. Two 48 hour intervals have been selected to represent typical conditions during the cruise. The first was collected between October 25 and 26, 1984, in the area between $32^{\circ} 47^{\prime} \mathrm{N}, 23^{\circ} 7^{\prime} \mathrm{W}$ and $335^{\circ} 5^{\prime} \mathrm{N}, 22^{\circ} 9^{\prime} \mathrm{W}$. These data were taken on a course between the Canary Islands and the Azores (Figure 2) under fair weather conditions with wind speeds less than $6 \mathrm{~m} / \mathrm{s}$ and broken trade wind cumuli ranging from 0 to 3 octas on the first day and from 0 to 6 octas on the second. The ship was on station from 0545 to 1405 UTC on the first day and from 0735 to 1830 UTC on the second day. The $2 \mathrm{~m}$ bulk temperatures varied between $22.0^{\circ}$ and $23.0^{\circ} \mathrm{C}$ (Figure $3 a$ ) indicating that the ship crossed an oceanic feature which may be a cold core mesoscale eddy in the middle of the series. Assuming a constant ship speed of $20 \mathrm{~km} / \mathrm{h}$, this feature has an horizontal length scale of about $120 \mathrm{~km}$. The bulk-skin temperature differences ranged between -0.65 and $0.3 \mathrm{~K}$ (Figure $3 a$ ) over this two day series.

The strong warming of the near-surface water, expressed by the two major negative peaks of $\Delta T$, is due to a high solar flux maximum exceeding $600 \mathrm{~W} / \mathrm{m}^{2}$ on the first day and even more on the second day (Figure $3 b$ ). In this case the net solar radiative flux was greater than the surface leaving turbulent and longwave fluxes, creating a diumal thermocline (Figure 1a). Strong cooling of the surface skin was observed during the early morning (8 UTC) and evening hours (20 UTC) of the first day, when longwave and latent heat fluxes reach their peak values due to increased wind speeds (Figure 3c). The early moming hours (610 UTC) of the second day were influenced by increasing cloud cover (Figure $3 c$ ), which protected the surface skin from excessive cooling by increased longwave downwelling irradiance and diminished latent heat flux. After sunrise the increasing solar flux led to a warming of the near surface layers. The warming exceeded that of the previous day since the wind induced mixing of the water was reduced (weaker wind maximum). At 13 UTC the temperature at $2 \mathrm{~m}$ was $0.1 \mathrm{~K}$ higher than that at $4 \mathrm{~m}$ and $7 \mathrm{~m}$. During the afternoon, $\Delta \mathrm{T}$ again returned to negative values. Figure $3 d$ shows $\Delta \mathrm{T}$ at a higher temporal resolution for the same time period. The $\Delta T$ values have been averaged over $5-\mathrm{min}$ intervals, during which the ship traveled a distance of $1.7 \mathrm{~km}$. This corresponds to the horizontal scales seen by satellite radiometers. The variation of $\Delta \mathrm{T}$ at this scale is larger than that shown above for the hourly averages, and $\Delta \mathrm{T}$ can deviate by 0.1 $\mathrm{K}$ from the hourly mean.

Further discussion is necessary to explain the strong negative peak observed on the first day when the wind speed was well above $5 \mathrm{~m} / \mathrm{s}$. This wind speed should be sufficient to suppress the establishment of a diurnal thermocline. This wind mixing was possibly restricted in the field of view of the radiometer which was looking to the lee side of the ship during the oceanographic station where the recorded wind velocity was reduced. Hence, the turbulent fluxes shown in Figure $3 b$ are only roughly related to $\Delta \mathrm{T}$ in Figure $3 a$ during the station hours. Cases like this one have been excluded from further analyses.

A second two day time series was collected from November 14 to 15,1984 , between $25^{\circ} 1^{\prime} \mathrm{N}, 20^{\circ} 10^{\prime} \mathrm{W}$ and $21^{\circ} 24^{\prime} \mathrm{N}, 19^{\circ} 24^{\prime} \mathrm{W}$. The $2 \mathrm{~m}$ bulk temperature ranged from $20.4^{\circ}$ to $23.4^{\circ} \mathrm{C}$ (Figure $4 a$ ) and exhibited strong horizontal gradients during this segment with imbedded small scale features. Again a mesoscale "cold core" was crossed by the ship. The bulk-skin temperature difference starts at about $\Delta \mathrm{T}=0.6 \mathrm{~K}$ at the beginning of this series (Figure $4 a$ ), associated with clear sky conditions and wind speeds of about $11 \mathrm{~m} / \mathrm{s}$ (Figure $4 c$ ). The surface leaving heat flux exceeds $400 \mathrm{~W} / \mathrm{m}^{2}$ due mainly to latent and longwave heat transfers (Figure $4 b$ ). As soon as the wind speed decreased during the next few hours the turbulent fluxes decreased, leading to smaller values of $\Delta \mathrm{T}$. These conditions change again between 5 and 8 UTC. After sunrise the total heat flux Q increases, reaching positive values near noon. However, $\Delta \mathrm{T}$ does not become negative because wind induced mixing of the upper ocean is still high enough to transport the solar heated upper water masses to greater depths. In addition, excessive cooling of the skin is prevented by increased cloud cover. This implies higher downwelling longwave irradiances and larger atmospheric humidity, causing the latent heat flux from the ocean into the atmosphere to decrease. The minimum of $\Delta \mathrm{T}$ is near $0.05 \mathrm{~K}$.

During the following night the wind speed rises again to values between 8 and $10 \mathrm{~m} / \mathrm{s}$. High latent heat flux and increased longwave flux into the atmosphere under decreased cloud cover cool the skin down, enhancing $\Delta \mathrm{T}$ to values between 0.3 and 0.8 $K$. The sensible heat flux $H$ plays a minor role because of the low temperature difference between the sea surface and the air. The relative minimum of $\Delta \mathrm{T}$ at $3 \mathrm{UTC}$ is accompanied by a minimum of $Q$ at night. During the daylight hours of the next day, $\Delta \mathrm{T}$ decreases due to increasing wind speed and higher solar radiation. The vertical mixing of the upper ocean is again strong enough to prevent $\Delta \mathrm{T}$ from reaching negative values. With decreasing net flux $Q, \Delta T$ returns to values near $0.5 \mathrm{~K}$ the following night.

The two time series shown are typical cases with large diumal variations of $\Delta T$ over horizontal distances smaller than $1000 \mathrm{~km}$. They suggest that small oceanic features can be hidden by the difference between bulk and skin temperature when observing the ocean with satellite infrared radiometry. In this case the "noise" introduced by the $\Delta \mathrm{T}$ differences masks the horizontal temperature gradients in bulk temperature. 

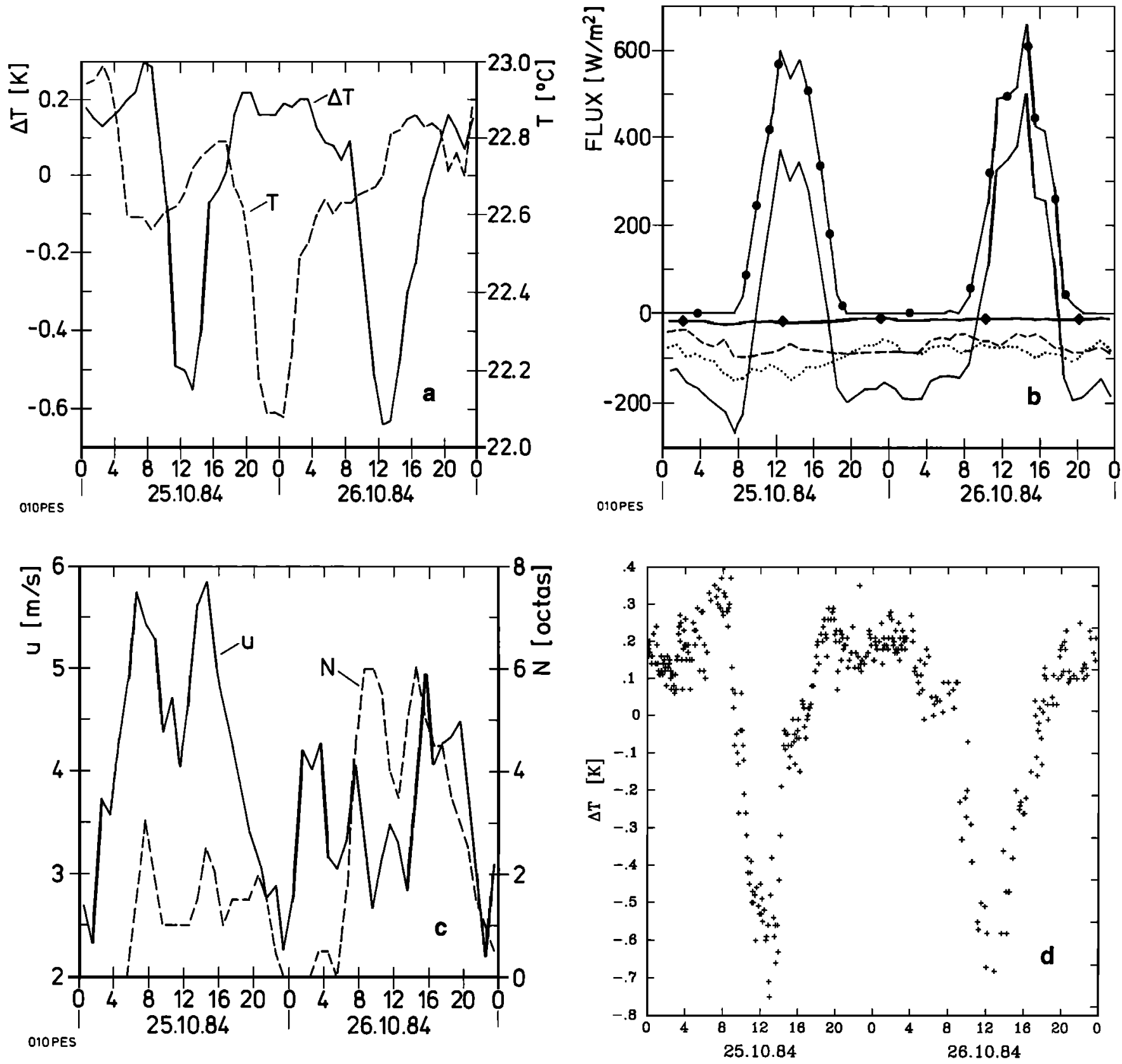

Fig 3. Two day-long time series on October 25 and 26, 1984. (a) Hourly means of $\Delta \mathrm{T}$ (solid line) and $2 \mathrm{~m}$ bulk temperature (T). (b) Hourly means of shortwave ( $\bullet$ ), longwave (dashed), latent (dotted), sensible ( $\bullet$ ) and total (solid) heat fluxes. (c) Hourly means of wind speed $(\mathrm{U})$ and cloud cover (solid line). (d) Five-minute means of $\Delta \mathrm{T}$.

\section{ParameterizatTon of $\Delta T$}

Following Saunders [1967] the bulk-skin temperature difference should be subject to both the net surface heat flux and the momentum flux. For negligible solar fluxes, i.e., night conditions, he relates $\Delta \mathrm{T}$ by dimensional analysis to the ratio of net flux $Q$ and the square root of the kinematic stress $\tau / \rho_{\mathbf{w}}$ :

$$
\Delta \mathrm{T}=\lambda \mathrm{Q} v /\left(\mathrm{k} \sqrt{\tau / \rho_{\mathrm{W}}}\right)
$$

where $\rho_{w}$, sea water density; $v$, the kinematic viscosity of sea water; $k$, the thermal conductivity of sea water; and $\lambda$, wind dependent numerical coefficient. Knowing the dependency of $\lambda$ on the wind speed, one could try to predict $\Delta \mathrm{T}$ from heat and momentum flux estimates based on actual measurements of the synoptic variables in (1) - (3), together with the longwave radiative flux. Grassl [1976] gives values of $\lambda$ for wind speeds between 1 and $10 \mathrm{~m} / \mathrm{s}$ computed from data measured in the tropical Atlantic. His $\lambda$ coefficients vary between $\lambda=2.2$ and $\lambda=$ 5.5. Saunders [1967] suggests $\lambda$ values between 5 and 10. This parameterization does not account for the influence of shortwave radiation as has been addressed by Hasse [1971]. He suggests an estimate for $\Delta T$, valid during both day and nighttime, as:

$$
\Delta \mathrm{T}=\mathrm{C}_{1}(\mathrm{~L}+\mathrm{H}+\mathrm{E}) / \mathrm{u}+\mathrm{C}_{2} \mathrm{~S} / \mathrm{u}
$$

with coefficients $C_{1}$ and $C_{2}$ depending on the reference depth where the bulk water temperature is measured. 

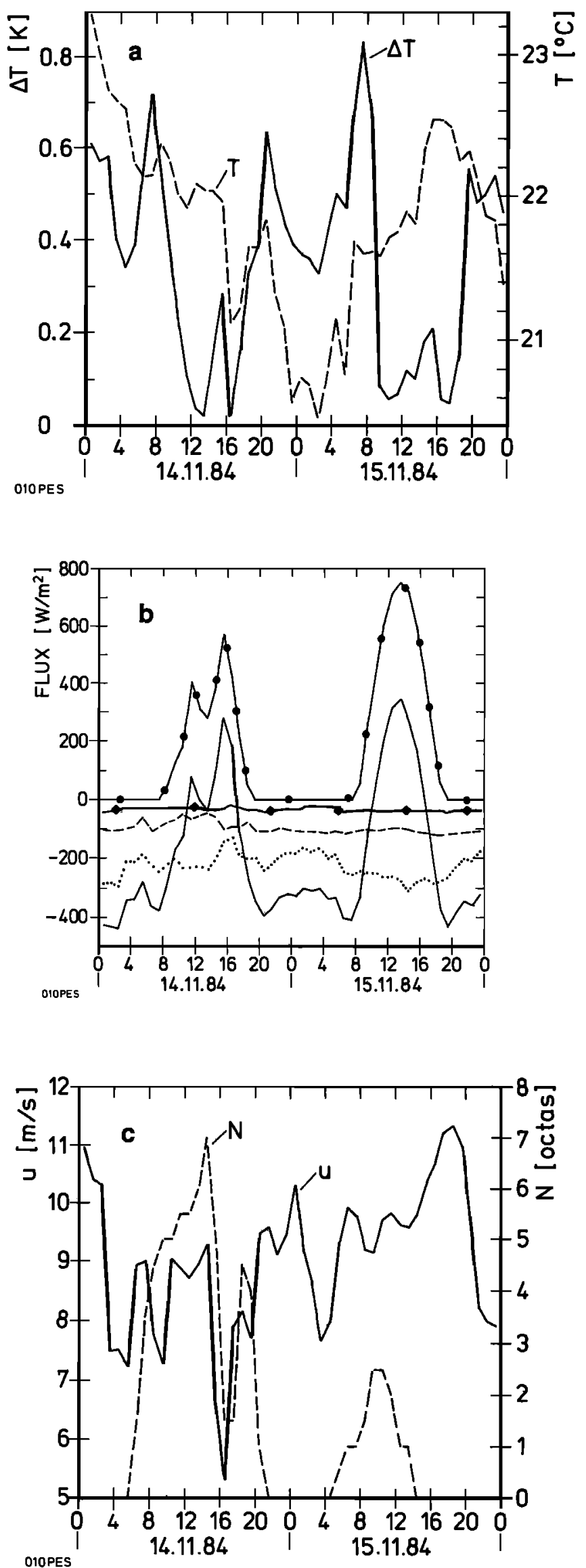

Fig. 4. Two day time series on November 14 and 15, 1984. (a) - (c) See Figure 3
Separating the hourly mean nighttime values and fitting them to (9) gives a poor correlation of 0.26 for a constant $\lambda=4.5$. Therefore we varied $\lambda$ with wind speed seeking for the best relationship between the left- and right-hand sides of (9) as was done by Grassl [1976]. However, the values found by Grass] for the tropical Atlantic do not seem to fit here. They give $\Delta T$ values that are too high at low wind speeds and cause an underestimate at higher wind speeds. For $1 \mathrm{~m} / \mathrm{s}$ intervals, $\lambda$ was recomputed yielding the values for the current dataset given in Table 1. Values of $\lambda$ increase with wind speed from 1 to 8 .

TABLE 1. Dependency of $\lambda$ on Wind Speed

\begin{tabular}{cc}
\hline$u(\mathrm{~m} / \mathrm{s})$ & $\lambda$ \\
\hline 1 & 1.1 \\
2 & 2.2 \\
3 & 2.2 \\
4 & 2.0 \\
5 & 2.9 \\
6 & 4.0 \\
7 & 4.5 \\
8 & 4.7 \\
9 & 5.9 \\
10 & 8.0 \\
11 & 8.4 \\
\hline
\end{tabular}

Using equation (9) now gives a correlation of 0.75 between its left- and right-hand sides, making $\Delta \mathrm{T}$ predictable to $0.13 \mathrm{~K}$. A scatter plot of this relation is shown in Figure $5 a$, demonstrating that extreme values of $\Delta \mathrm{T}$ cannot be handled properly by this approach. Since all flux contributions are weighted by the same factor $\lambda$, equation (9) tends to yield $\Delta \mathrm{T}$ values within a small range about the mean value. The Hasse [1971] estimate was also tested for data at night but gave a poor correlation of $\mathbf{0 . 3 0}$ between $\Delta \mathrm{T}$ and $(\mathrm{L}+\mathrm{E}+\mathrm{H}) / \mathrm{u}$. During sunlight hours, equation (10) performs slightly better, with a correlation of 0.64 , allowing one to estimate $\Delta T$ to an accuracy of $0.19 \mathrm{~K}$. Another approach was tested which allowed each of the fluxes, or their related parameters, to contribute to the prediction formula with their individual weights. Starting with equation (10), single fluxes, or fluxes divided by the wind speed to account for vertical mixing, were entered into the stepwise multiple regression to yield $\Delta T$.

For nighttime we found the best estimate of $\Delta \mathrm{T}$ to be

$$
\Delta T=a_{0}+a_{1} u\left(T_{s}-T_{a}\right)+a_{2} u\left(q_{s}-q_{a}\right)+a_{3} L
$$

where $\mathrm{T}_{\mathrm{a}}$ is air temperature at $20 \mathrm{~m}$. The coefficients $\mathrm{a}_{0}=-0.285$ $\mathrm{K}, \mathrm{a}_{1}=0.0115 \mathrm{~s} / \mathrm{m}, \mathrm{a}_{2}=37.255 \mathrm{~K}$, and $\mathrm{a}_{3}=-0.00212 \mathrm{~km}^{2} / \mathrm{W}$ were optimized to predict $\Delta \mathrm{T}$ with an accuracy of $0.10 \mathrm{~K}$. Figure $5 b$ emphasizes that this kind of parameterization is able to also handle extreme $\Delta T$ values. Restricting the fit to only the first three terms on the right side of (11), which includes only standard meteorological variables, the optimized coefficients become a $=$ $-0.125 \mathrm{~K}, \mathrm{a}_{1}=0.0118 \mathrm{~s} / \mathrm{m}$, and $\mathrm{a}_{2}=41.391 \mathrm{~K}$. The estimated error in $\Delta \mathrm{T}$ is then $0.11 \mathrm{~K}$. During daytime, having included a term for the solar flux, we obtain the following model as the best prediction for $\Delta \mathrm{T}$ :

$$
\Delta T=a_{0}+a_{1} S / u+a_{2}\left(q_{s}-q_{a}\right)+a_{3} L
$$

where $a_{0}=-0.415 \mathrm{~K}, a_{1}=-0.00337 \mathrm{~km}^{3} / \mathrm{sW}$, a $=48.043 \mathrm{~K}$, and $a_{3}=-0.00355 \mathrm{~km}^{2} / \mathrm{W}$. The standard error for this formulation is $0.17 \mathrm{~K}$ (Figure $5 c$ ). 


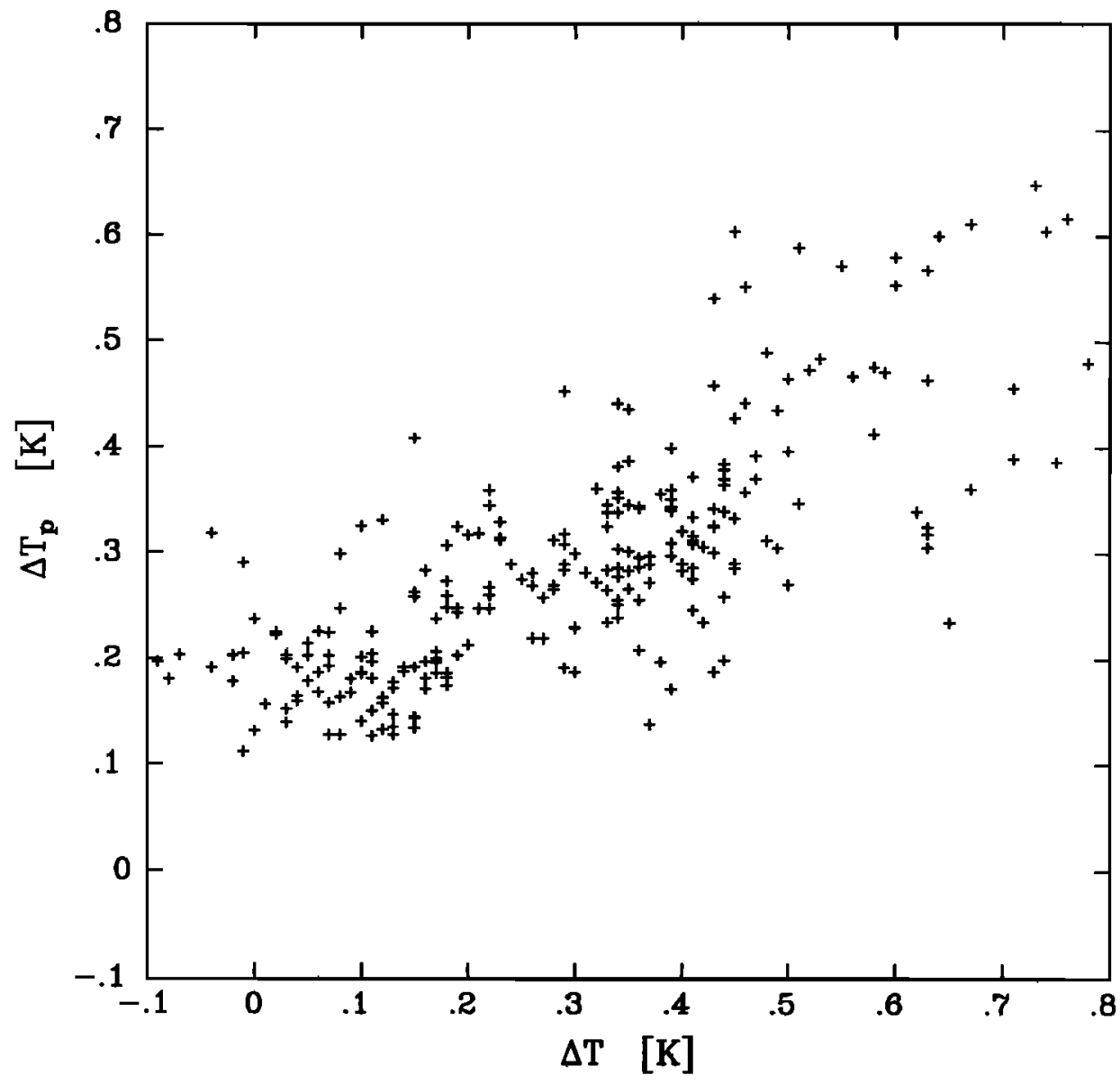

a

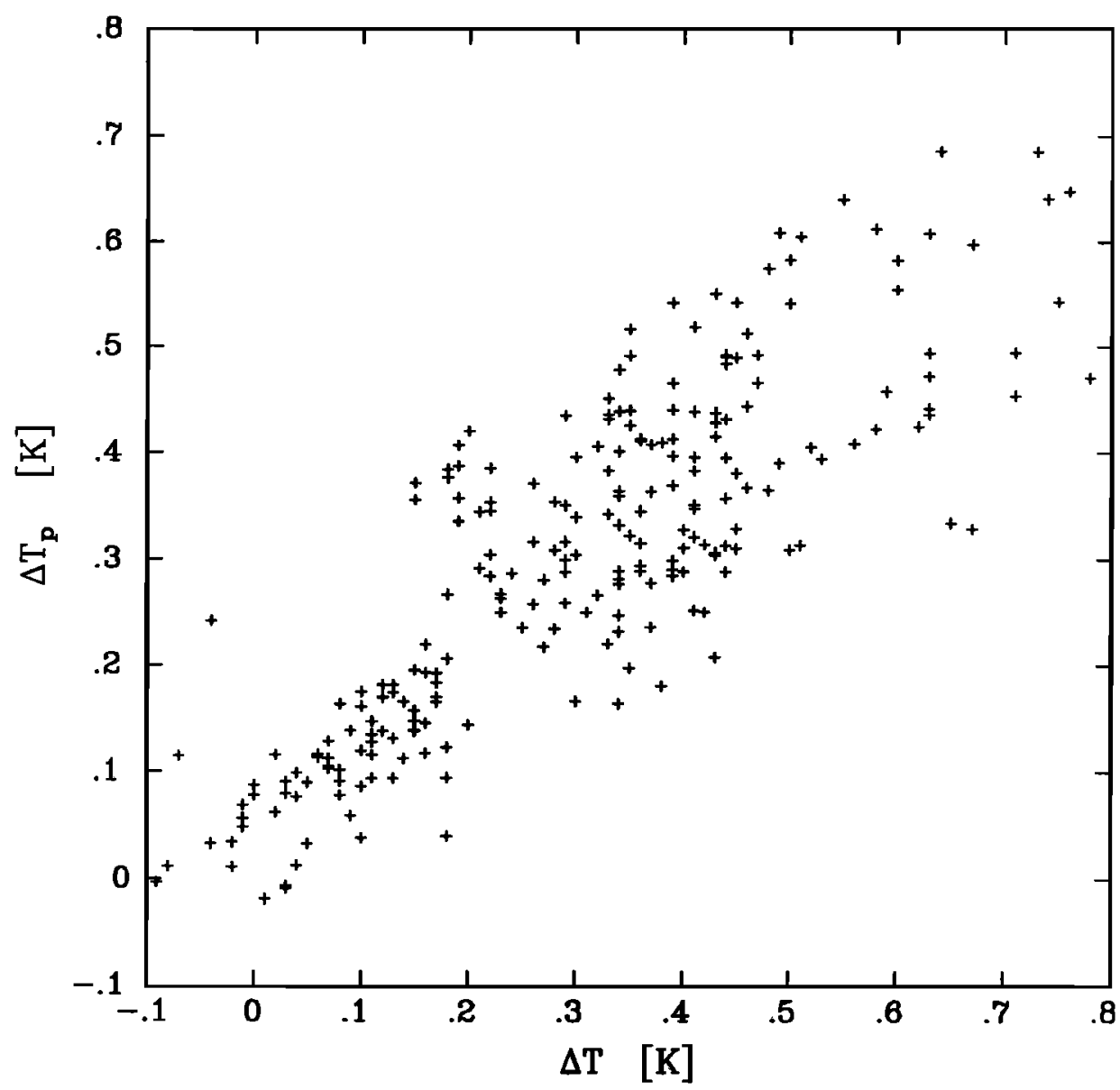

b

Fig 5. Bulk versus skin temperature differences during night as observed $(\Delta T)$ and parameterized $\left(\Delta T_{p}\right)$ with $(a)$ equation $(9)$, (b) equation (11), and (c) equation (12). 


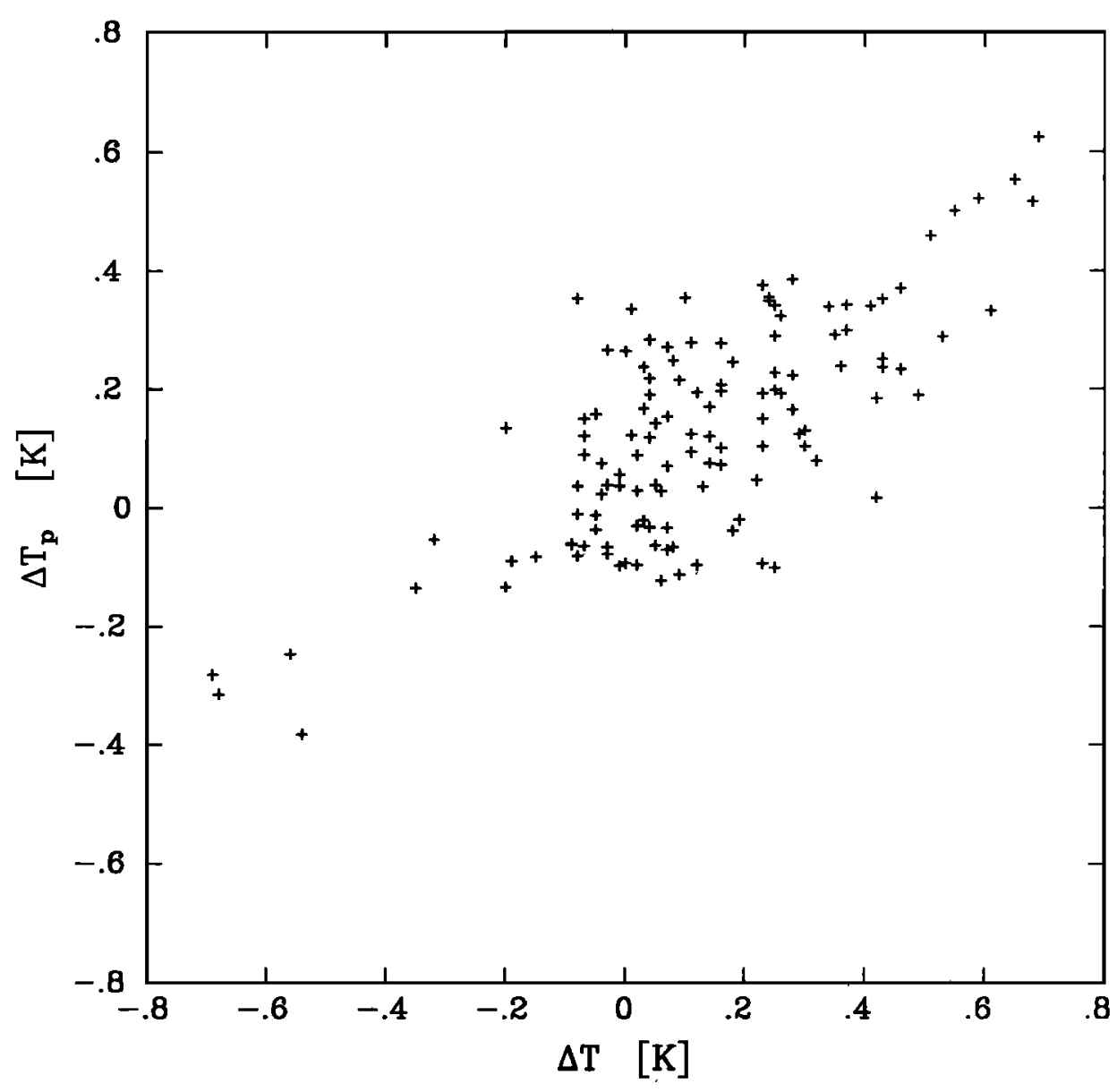

Fig. 5. (continued)

\section{DISTRIBUTION OF $\Delta T$}

The purpose of this section is to present relative distributions of $\Delta \mathrm{T}$ during the cruise and to identify mean $\Delta \mathrm{T}$ values under conditions which can easily be identified in order to derive corrections that should be applied to satellite-derived skin temperatures when bulk SST's are desired. We start with some overall distributions of $\Delta T$ with respect to different depths where the bulk water temperatures were measured (Figure 6). All temperature differences were averaged over 5-min intervals and resampled into classes of $0.1 \mathrm{~K}$ width. The shallowest bulk temperature could be collected only while the ship was drifting on station under good weather conditions or while the ship travelled at very low speed. This platinum resistance thermometer was deployed under a styrofoam float which would jump out of the water above a certain ship speed. Thus the number of measurements at this depth is rather small (515 values). The number of 5-min samples for the other depths is on the order of 5000 .

All histograms exhibit distributions with a mean between 0.1 and $0.2 \mathrm{~K}$ and variations between -1.0 and $1.0 \mathrm{~K}$. Figure $6 a$ represents a variety of fair weather conditions only but still occupies almost the full range of differences that occurred during the entire cruise. The histograms for $\Delta T$, at the deeper levels, look very similar. We show only the histogram for the $2 \mathrm{~m}$ bulk temperature (Figure $6 b$ ). About $80 \%$ of the measurements lie between -0.1 and $0.5 \mathrm{~K}$. The mean differences between the temperature measured at $2 \mathrm{~m}$ and that at $4 \mathrm{~m}$ and $7 \mathrm{~m}$ are -0.065 $\mathrm{K}$ and $-0.050 \mathrm{~K}$, respectively, demonstrating the mean cooling of the surface. The temperature at $4 \mathrm{~m}$ is probably influenced by the warmth of the ship's engine room near the location of the $4 \mathrm{~m}$ thermometer leading to temperatures that are about $0.04 \mathrm{~K}$ too high.

Despite the fact that a parameterization of $\Delta T$ in terms of heat and momentum fluxes, or their related parameters, is the most useful for finding a correction to satellite sensed skin temperatures when bulk temperatures are desired, it is not practical. The input values to compute the fluxes are normally not available on an operational basis, and the discussion of the sample time series has shown that $\Delta \mathrm{T}$ might vary dramatically within small spatial and temporal scales, making climatological values of the fluxes inappropriate. Information that can be estimated (from the satellite data themselves) to compute $\Delta T$ for the correction of satellite derived skin SST's are the local time and the cloud cover(N). From the time series studied it is obvious that $\Delta T$ behaves differently during day and night times. At night the skin cooling is the dominant process (except in very rare cases where $Q$ is positive), while in the daytime, solar heating becomes important, leading to a warming of the top layer of the ocean that might result in a skin that is warmer than the bulk temperature at a depth of several meters.

A division of the total data set into day and night shifts the distribution of the histograms (further references are to the $2 \mathrm{~m}$ bulk temperature). The daytime mode value of $\Delta T$ is between 0.0 and $0.1 \mathrm{~K}$, while at night the distribution peaks between $0.1 \mathrm{~K}$ and $0.2 \mathrm{~K}$ (Figure 7). The different skewness of the day and night distributions emphasizes the strong nocturnal cooling of the surface, while during daylight hours both cooling and heating may occur: cooling by longwave and turbulent fluxes as well as 

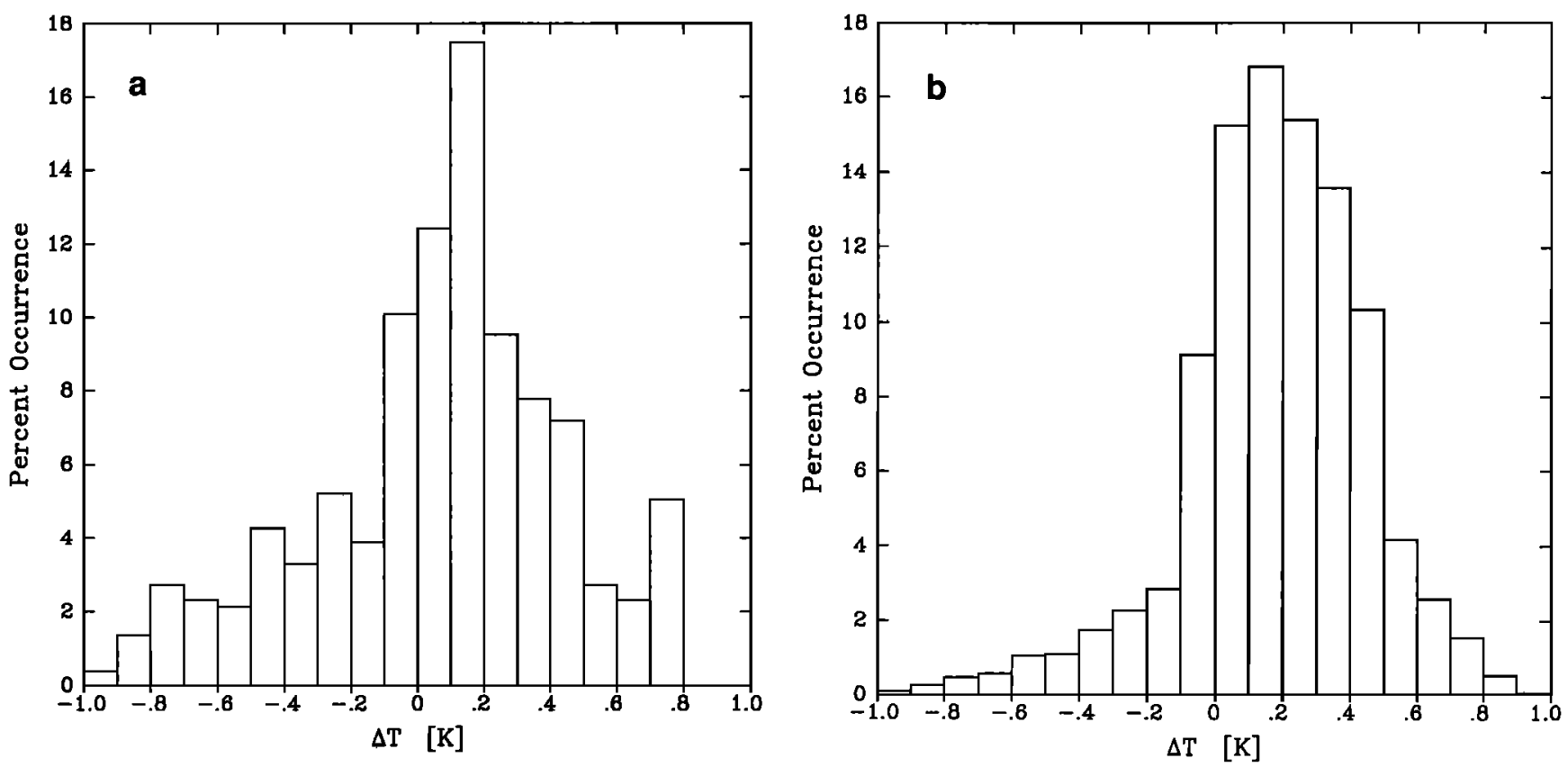

Fig 6. Distribution of five-minute means of $\Delta \mathrm{T}$ : (a) with respect to $0.1 \mathrm{~m}$ bulk temperature during good weather conditions only, (b) with respect to $2 \mathrm{~m}$ bulk temperature.

higher temperatures, below the molecular skin layer, leading to negative $\Delta \mathrm{T}$ values. The mean value of $\Delta \mathrm{T}$ shifts from $0.3 \mathrm{~K}$ at night to $0.11 \mathrm{~K}$ during day.

The data were also stratified in terms of the cloud cover $\mathbf{N}$ observed hourly (in octas). While clouds mainly modify the radiation field (both short and longwave), there is no obvious impact of $\mathbf{N}$ on the turbulent fluxes in our data. The solar radiation into the ocean is decreased by the presence of clouds when $\mathrm{N}$ becomes larger than $5 / 8$, while the longwave portion of the downwelling irradiance increases with $N$, starting with small

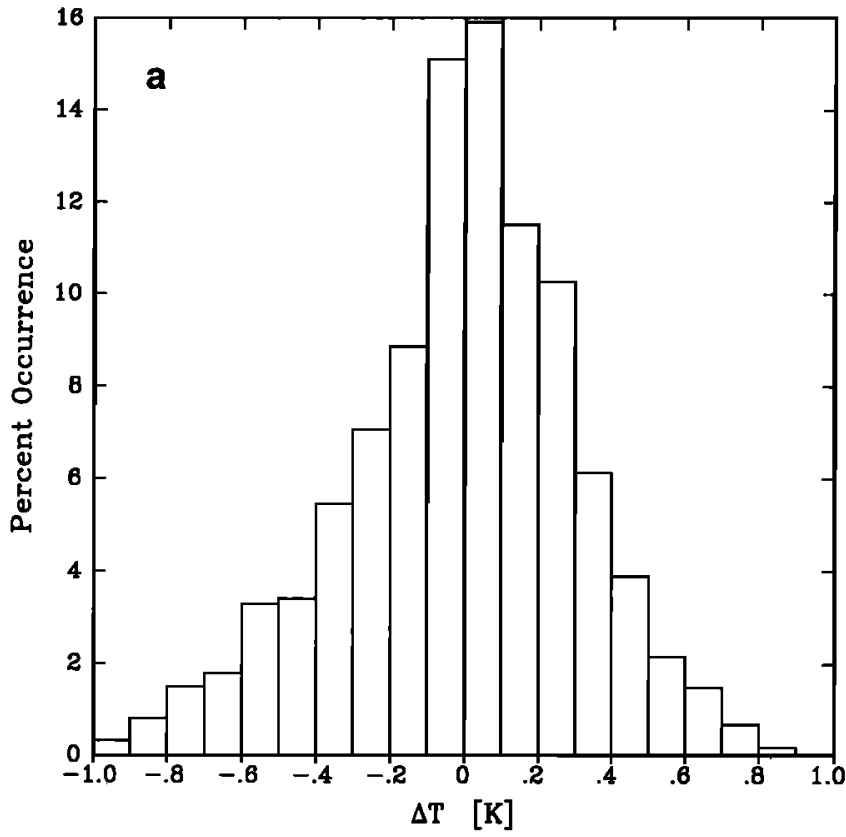

values of N. Also, a lowering of the cloud base (seen by separating clouds into classes "low", "middle", and "high") and a moistening of the air will increase the downwelling longwave irradiance.

The dependence of $\Delta T$ on cloud cover is best presented by histograms as shown in Figure 8. Since adjacent octas from observed cloud cover are not significantly different, we first separate our data into only four different classes, divided into day and night distributions of $\Delta T$ for $N$ between 0 and 5 or between 6 and 8 octas. The corresponding mean $\Delta T$ values are given in

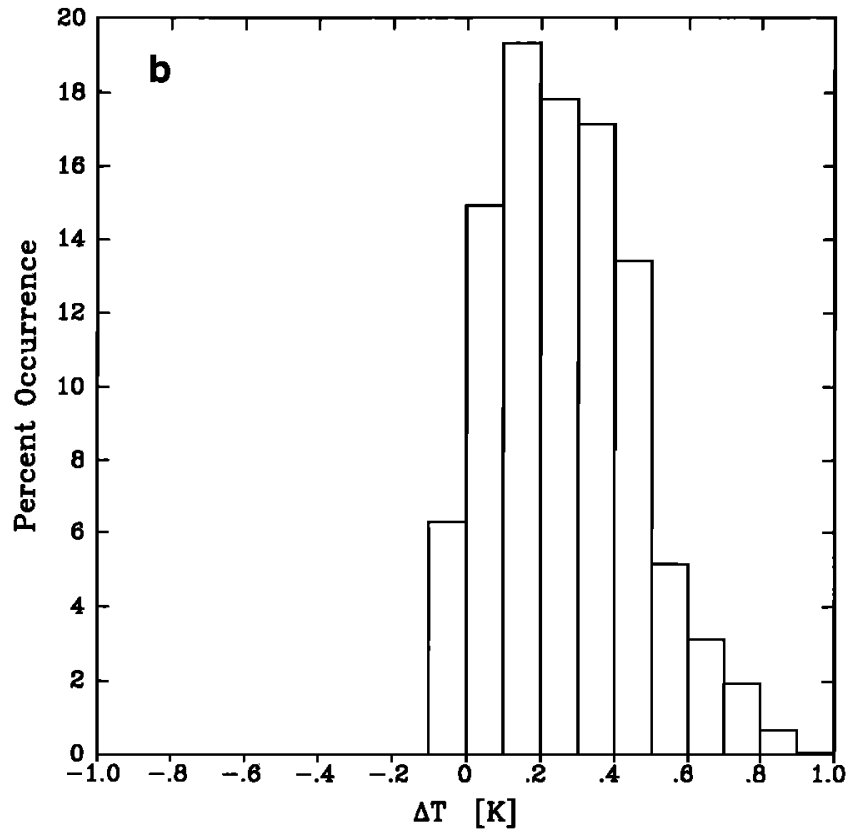

Fig 7. Distribution of five-minute means of $\Delta T$. (a) Day. (b) Night. 

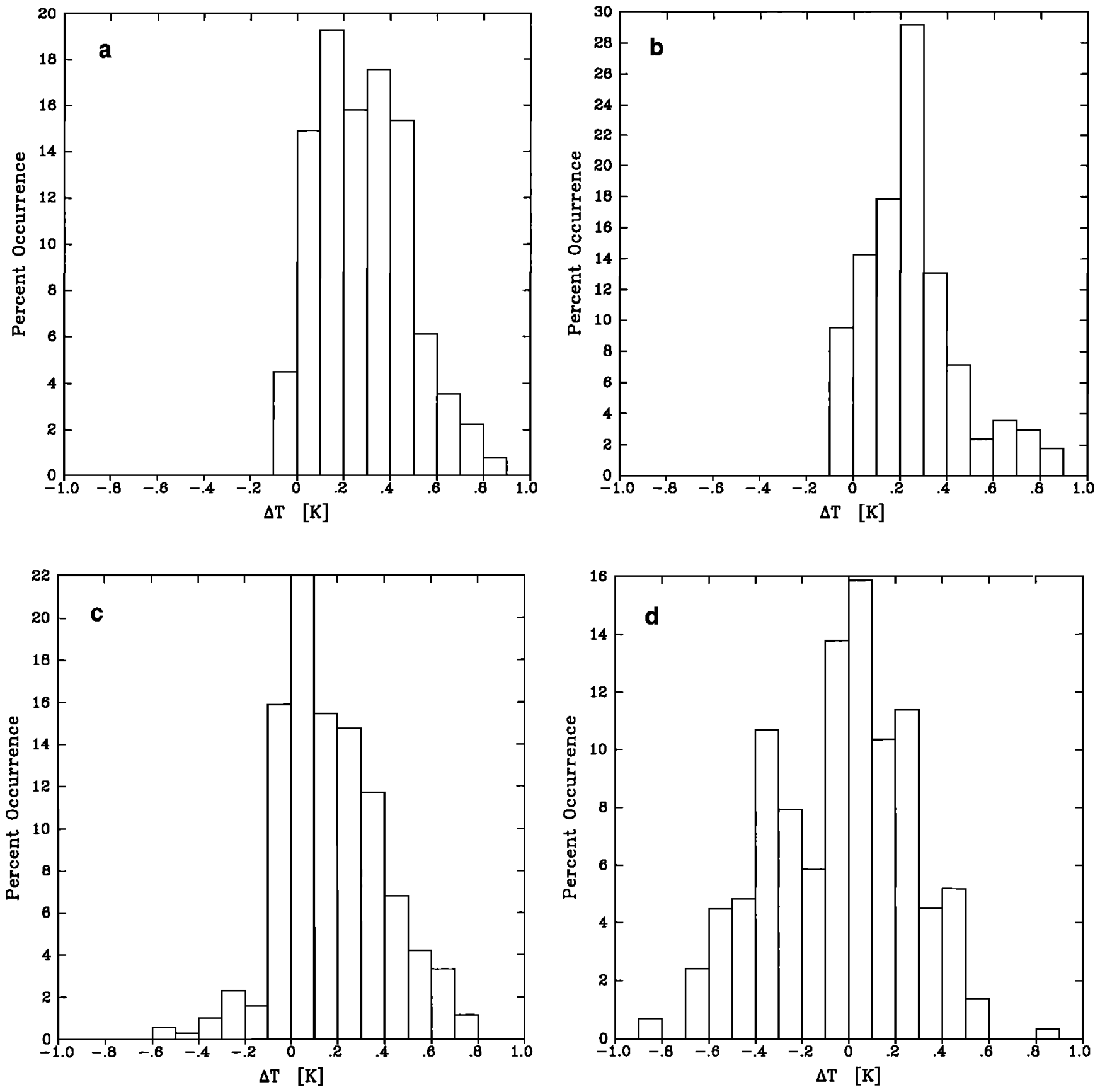

Fig 8. Distribution of five-minute means of $\Delta \mathrm{T}$. (a) Night, $\mathrm{N}=0-5$ octas. (b) Night, $\mathrm{N}=6-8$ octas. (c) Day, $\mathrm{N}=0-5$ octas. (d) Day, $\mathrm{N}=6-8$ octas.

Table 2. Their standard deviations are between 0.2 and $0.25 \mathrm{~K}$. At night, under low cloud cover, $\Delta \mathrm{T}$ mainly varies between 0 and $0.5 \mathrm{~K}$ with a mean value of $0.28 \mathrm{~K}$.

The two modes identified can be separated by their dependence on the wind speed. Lower wind speeds (separation at $5 \mathrm{~m} / \mathrm{s}$ ) correspond to lower $\Delta \mathrm{T}$ values (Table 3 ). At high cloud cover, $\Delta \mathrm{T}$ has a narrower distribution, varying mainly between 0 and 0.4 $\mathrm{K}$, with a mode value between 0.2 and 0.25 and a mean at $0.26 \mathrm{~K}$. Again a split in high and low wind conditions separates two clusters in the histogram, with means of 0.28 and $0.22 \mathrm{~K}$ for high and low wind conditions respectively (Table 3 ). The daytime histograms for the different cloud classes show a broad distribution at high $N$, with the highest population between -0.4 and $0.3 \mathrm{~K}$ and the main mode between 0 and $0.1 \mathrm{~K}$. The mean value under these high cloud cover conditions lies at $0.05 \mathrm{~K}$. Knowledge of the wind speed could again separate two clusters for low and high wind situations with cluster means of $-0.07 \mathrm{~K}$ and $0.16 \mathrm{~K}$, respectively. During low cloud cover conditions the distribution becomes narrower, peaking between 0.0 and $0.1 \mathrm{~K}$ with a mean at $0.23 \mathrm{~K}$. Separating this into two wind speed classes gives a mean of $0.23 \mathrm{~K}$ for high winds and $0.17 \mathrm{~K}$ for low winds.

The standard deviations corresponding to the $\Delta \mathrm{T}$ values given in Table 3 are smaller, ranging from 0.15 to $0.2 \mathrm{~K}$; however they 
TABLE 2. Mean $\Delta T$ Values for Different Cloud Cover and Diumal Conditions

\begin{tabular}{ccc}
\hline $\mathrm{N}$ (octas) & Day & Night \\
\hline $0-5$ & $0.23 \mathrm{~K}$ & $0.28 \mathrm{~K}$ \\
$6-8$ & $0.05 \mathrm{~K}$ & $0.26 \mathrm{~K}$ \\
\hline
\end{tabular}

TABLE 3. Mean $\Delta T$ Values for Various Cloud, Daytime, and Wind Speed Conditions

\begin{tabular}{cccc}
\hline $\mathrm{N}$ (octas) & $\mathrm{u}(\mathrm{m} / \mathrm{s})$ & Day & Night \\
\hline $0-5$ & $>5$ & $0.23 \mathrm{~K}$ & $0.33 \mathrm{~K}$ \\
$0-5$ & $<5$ & $0.17 \mathrm{~K}$ & $0.18 \mathrm{~K}$ \\
$6-8$ & $>5$ & $0.16 \mathrm{~K}$ & $0.28 \mathrm{~K}$ \\
$6-8$ & $<5$ & $-0.07 \mathrm{~K}$ & $0.22 \mathrm{~K}$ \\
\hline
\end{tabular}

require not only a knowledge of $\mathrm{N}$ but also an estimate of $\mathrm{u}$. The obvious day-night variations of the skin effect become important when investigating diumal variability of sea surface temperatures from infrared imagery as done by Cornillon and Stramma [1985]. Part of this variability might be attributed to the skin effect, while another portion is enhanced by the diurnal thermocline.

\section{Correllation and Spectrai. ANALYsis}

For remotely sensed SST's the question arises, are the skin temperatures, seen by satellite radiometers, representative of the temperatures at deeper levels of the ocean? Many of the well known ocean circulation features are clearly expressed in infrared satellite imagery. The foregoing discussions have shown that for small scales the changing skin effect might hide variations in bulk SST's when observing the sea surface radiometrically. This could perturb the calibration "match-ups" done between buoy measurements at a single location and the satellite-derived SST from a coincident single pixel.

Insight into the coupling between skin and bulk temperatures at different space scales can be gained by looking at the correlations between these two parameters for ship tracks of different lengths. Dividing our data record from the moving ship into linear sections of between $\Delta x=20 \mathrm{~km}$ and $\Delta x=640 \mathrm{~km}$ the mean cross correlation between skin temperature and the bulk temperature at $2 \mathrm{~m}$ rises from 0.5 for the short scales to over 0.9 for the longest tracks (Table 4). The range of correlations is largest for the short segments and monotonically decreases as the lengths of the tracks increase. Thus at longer scales $(>80 \mathrm{~km})$ one can expect the surface skin temperature variations to represent the ocean variability reflected by the bulk temperatures. At shorter scales, skin and bulk temperatures are only weakly correlated.

These cross correlations between bulk and skin temperatures, over various segments of the overall cruise track, suggest a

TABLE 4. Mean Correlations Between $T_{s}$ and $T_{2}$ and Their Standard Deviations (S. D.)

\begin{tabular}{ccc}
\hline$\Delta \times(\mathrm{km})$ & Correlation & S. D. \\
\hline 20 & 0.5 & 0.36 \\
40 & 0.62 & 0.33 \\
80 & 0.74 & 0.29 \\
160 & 0.85 & 0.21 \\
320 & 0.92 & 0.02 \\
640 & 0.92 & 0.01 \\
\hline
\end{tabular}

further decomposition of the time series in terms of the coherence spectra between bulk and skin temperatures, again for different portions of the cruise track. The separation into cruise segments was an effort to keep the analysis of the time series consistent along straight sections of the track and to identify horizontal scales within the spectra being computed. The portions of the cruise track when the ship was steaming were strictly separated from the data collected at oceanographic stations where the ship remained relatively stationary. Unfortunately, the latter were quite short and often contaminated by local ship effects and therefore failed to provide a sufficiently wide range of periods to analyze.

The data series used for the spectral computations were those with the original 1 -min means. Coherence spectra were computed using cross covariances computed with a fast Fourier transform (FFT). For each of the time series a linear trend was removed, and a cosine taper was applied to $2.5 \%$ of the data at each end before the computation of the cross covariances. Spectral smoothing was accomplished with a Tukey lag window. The data collected with the ship underway were separated into six sections as described in Table 5. Segment 6 is the southern part of segment 5 . The first three segments are essentially zonally oriented (Figure 2), while the last three are more meridional in their geographic alignment. The segments range in length from $350 \mathrm{~km}$ in segment 2 to over $3400 \mathrm{~km}$ in segment 5 . The first segment is a zonal track along about $37^{\circ} \mathrm{N}$ from the coast of Portugal out to about $22^{\circ} \mathrm{W}$. With an overall length of about $1190 \mathrm{~km}$ the coherence spectrum (solid line) computed for this segment (Figure 9a) levels out with a perfect correlation at a wavelength of about $320 \mathrm{~km}$. From this maximum correlation the coherence spectrum falls off rapidly with lower wavelengths, interrupted by intermediate peaks of 0.95 to 0.8 squared coherency near 160,110 , and $70 \mathrm{~km}$. The dashed lines bracketing the solid line represent the $95 \%$ confidence interval.

The overall decrease from the perfect coherence at the longest wavelengths to a minimum at the shortest wavelengths indicates that skin and bulk temperature are highly corrslated at longer length scales where oceanic features with strong gradients in their surface temperatures are not hidden by the skin effect. At the same time they are clearly not coherent for the shorter spatial scales; here the variation of bulk-skin temperature differences seems to be larger than horizontal signatures in the bulk temperatures. The same general pattern was found in all coherence spectra during this cruise. Thus satellite skin temperatures should represent well the larger spatial scales of the long-term and mesoscale ocean circulations. This also explains why infrared satellite imagery often clearly reflects the presence of mesoscale ocean circulations (eddies, meanders, fronts, etc.).

The intermediate coherence peaks, in Figure $9 a$, are thought to be due to the presence of ocean mesoscale eddies in this segment of the cruise track. There is some evidence of such mesoscale ocean eddies in previous data from this region [Gould, 1983]. It is not possible from our data alone to verify the dynamic nature of these features, but it appears reasonable to assume that the coherence at these wavelengths is duc to the temperature gradients within these eddies surmounting the skin effect. Almost the same appearance is present in track segment 5, which again has some intermediate mesoscale events in the coherence spectrum. The phase spectrum (not shown) corresponding to Figure $9 a$ (segment 1 ) is almost zero across the entire range of wavelengths, indicating that both bulk and skin temperatures vary in phase. Figure $9 b$ contains the coherence spectrum for the shortest segment (segment 2). Similar to segment 1 , the overall pattern is a decrease from highest coherence at the longest wavelengths. 
TABLE 5. Description of Cruise Segments for Which Coherence Spectra Were Computed

\begin{tabular}{|c|c|c|c|c|c|}
\hline $\begin{array}{l}\text { Segment } \\
\text { Number }\end{array}$ & $\begin{array}{l}\text { Start Date } \\
1984 \\
\text { Time } \\
\text { (UTC) }\end{array}$ & $\begin{array}{l}\text { Start } \\
\text { Position }\end{array}$ & $\begin{array}{l}\text { End Date } \\
1984 \\
\text { Time } \approx \\
\text { (UTC) }\end{array}$ & $\begin{array}{l}\text { End } \\
\text { Position }\end{array}$ & Length (km) \\
\hline 1 & $\begin{array}{l}\text { Oct. } 20 \\
1955\end{array}$ & $\begin{array}{l}38^{\circ} 35^{\prime} \mathrm{N} \\
9^{\circ} 30^{\prime} \mathrm{W}\end{array}$ & $\begin{array}{l}\text { Oct. } 23 \\
2030\end{array}$ & $\begin{array}{l}36^{\circ} 00^{\prime} \mathrm{N} \\
22^{\circ} 30^{\prime} \mathrm{W}\end{array}$ & 1190 \\
\hline 2 & $\begin{array}{l}\text { Oct. } 27 \\
2005\end{array}$ & $\begin{array}{l}35^{\circ} 53^{\prime} \mathrm{N} \\
22^{\circ} 53^{\prime} \mathrm{W}\end{array}$ & $\begin{array}{l}\text { Oct. } 29 \\
1435\end{array}$ & $\begin{array}{l}35^{\circ} 03^{\prime} \mathrm{N} \\
26^{\circ} 35^{\prime} \mathrm{W}\end{array}$ & 350 \\
\hline 3 & $\begin{array}{l}\text { Oct. } 31 \\
1145\end{array}$ & $\begin{array}{l}28^{\circ} 00^{\prime} \mathrm{N} \\
26^{\circ} 29^{\prime} \mathrm{W}\end{array}$ & $\begin{array}{l}\text { Nov. } 5 \\
1920\end{array}$ & $\begin{array}{l}27^{\circ} 30^{\prime} \mathrm{N} \\
15^{\circ} 09^{\prime} \mathrm{W}\end{array}$ & 1150 \\
\hline 4 & $\begin{array}{l}\text { Nov. } 15 \\
1720\end{array}$ & $\begin{array}{l}20^{\circ} 50^{\prime} \mathrm{N} \\
18^{\circ} 44^{\prime} \mathrm{W}\end{array}$ & $\begin{array}{l}\text { Nov. } 18 \\
1545\end{array}$ & $\begin{array}{l}27^{\circ} 56^{\prime} \mathrm{N} \\
26^{\circ} 26^{\prime} \mathrm{W}\end{array}$ & 1160 \\
\hline 5 & $\begin{array}{l}\text { Nov. } 18 \\
2005\end{array}$ & $\begin{array}{l}28^{\circ} 00^{\prime} \mathrm{N} \\
26^{\circ} 26^{\prime} \mathrm{W}\end{array}$ & $\begin{array}{l}\text { Nov. } 27 \\
1400\end{array}$ & $\begin{array}{l}50^{\circ} 28^{\prime} \mathrm{N} \\
00^{\circ} 42^{\prime} \mathrm{E}\end{array}$ & 3410 \\
\hline 6 & $\begin{array}{l}\text { Nov. } 18 \\
2005\end{array}$ & $\begin{array}{l}28^{\circ} 00^{\prime} \mathrm{N} \\
26^{\circ} 26^{\prime} \mathrm{W}\end{array}$ & $\begin{array}{l}\text { Nov. } 22 \\
1500\end{array}$ & $\begin{array}{l}38^{\circ} 30^{\prime} \mathrm{N} \\
19^{\circ} 30^{\prime} \mathrm{W}\end{array}$ & 1330 \\
\hline
\end{tabular}

Unlike Figure $9 a$ the segment 2 coherence spectrum does not reach a perfect correlation value but rather only gets to a correlation of 0.4 at the longest length scales. There seem to be no strong oceanic temperature gradients exceeding the skin effect during this short segment. The phase spectrum is again almost zero. The coherence spectrum from segment 3 (Figure 9c) falls off precipitously from a high of about 0.8 near $320 \mathrm{~km}$ to a low of 0.1 at about $200 \mathrm{~km}$. This rapid drop indicates that for this essentially zonal cruise, segment skin and bulk temperatures will not be well correlated for length scales shorter than about 250 $\mathrm{km}$. At the same time, large-scale (greater than $280 \mathrm{~km}$ ) averages of skin and bulk temperatures are very well correlated. Again the phase spectrum is essentially constant at zero. There is some phase shift to negative values at length scales shorter than $200 \mathrm{~km}$ but the coherence values are so low in this range that there is no statistical significance in these phase shifts. The $95 \%$ confidence interval in the coherence spectrum is quite narrow around the maximum values and major spectral decrease.

High coherence at the longest wavelengths is also a feature of the coherence spectrum for segment 4 (Figure 9d). The spectral drop-off of this coherence is shifted to slightly higher wavelengths ( $300 \mathrm{~km}$ versus $280 \mathrm{~km}$ ) compared to segment 3 , and the maximum coherence values are slightly lower $(0.75$ versus 0.8). At wavelengths shorter than $300 \mathrm{~km}$, bulk temperatures are not coherent with skin temperatures. As with all previous cruise segments the phase spectrum for segment 4 is
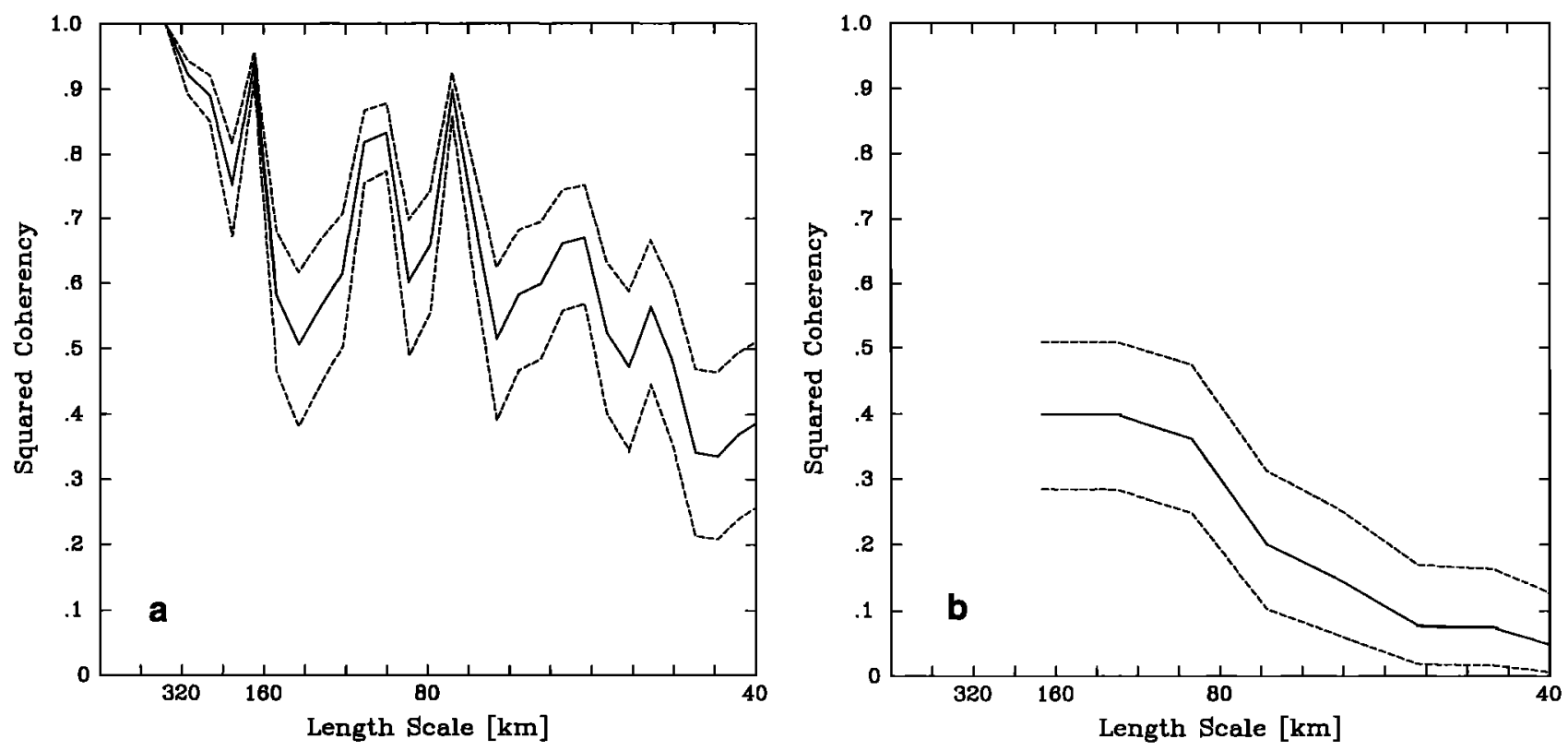

Fig 9. Spectra of squared coherencies (solid lines) for cruise segments 1 to 6 (Figures $9 a$ to $9 f$ respectively); dashed lines are the 95\% confidence intervals. 

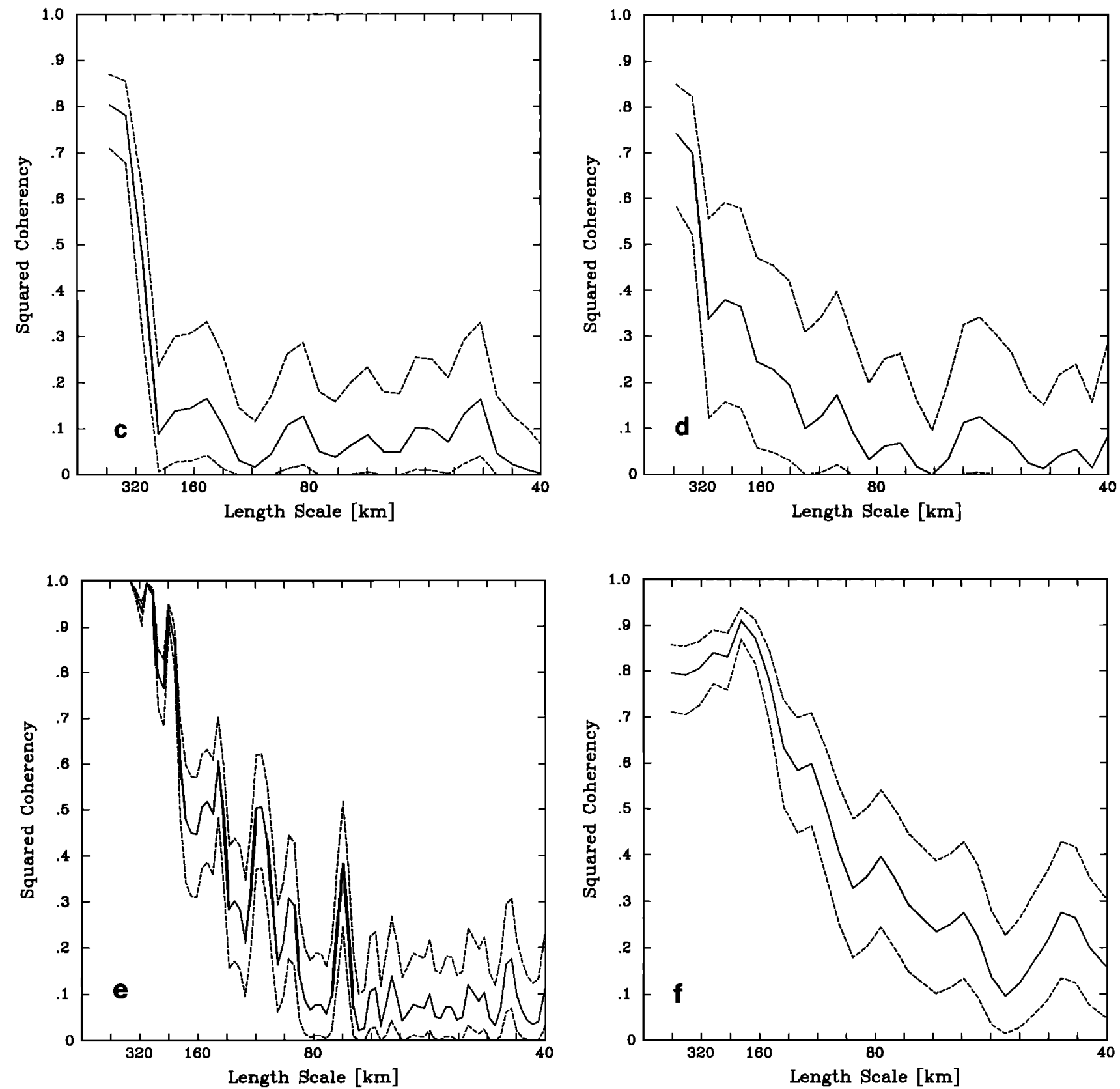

Fig 9. (continued)

nearly zero. Segment 5 contains the entire track from the Canary Basin to the English Channel. We also separated the southern part of segment 5 and analyzed it as segment 6 (Figure 9f). The coherence spectrum of segment 5 (Figure $9 e$ ) contains two peaks near 130 and $65 \mathrm{~km}$, while at longer wavelengths the coherence increases to 1 at scales longer than $320 \mathrm{~km}$. Wavelengths shorter than the intermediate peak at $65 \mathrm{~km}$ have much lower coherence values. As with segment 1 , the intermediate peaks are thought to be due to the presence of mesoscale ocean eddies. The high coherence at these scales indicates that satellite measured skin temperature should depict well the subsurface temperature structure of mesoscale eddies.

In segment 6 the coherence is high at wavelengths larger than
$240 \mathrm{~km}$ and drops off dramatically at shorter length scales. Both this and the segment 5 coherence spectrum have $95 \%$ confidence limits that are quite narrow at the higher coherences. Also, the phase spectra for both of these coherence spectra are essentially zero, indicating an in-phase relationship between bulk and skin temperatures.

Taking a coherency of $>0.7$ (corresponding to a squared coherency of $>0.49$ ) as a threshold defining a "good correspondence" between skin and bulk temperatures, we conclude that for length scales greater than $150 \mathrm{~km}$ the skin temperature is representative of the bulk temperature ocean variability even though individual skin-bulk temperature differences (at shorter wavelengths) show fluctuations on the 
order of $0.3 \mathrm{~K}$. This threshold length scale might shift to lower values in those areas where strong horizontal gradients of SST overwhelm the skin effect and/or the $\Delta T$ variations due to diumal thermoclines. On the other hand, even small horizontal temperature gradients might be detected in satellite images at large but constant bulk-skin temperature differences due to nearly homogeneous horizontal distributions of heat and momentum fluxes through the surface. These conditions can often be observed in infrared images where large areas are synoptically scanned and which do not show the temporal variation of $\Delta \mathrm{T}$ as seen in the time series taken by the ship measurements.

\section{Conclusion AND Discussion}

An analysis of shipborne measurements of bulk-skin temperature differences during a six week cruise in the North Atlantic has shown $\Delta \mathrm{T}$ values varying between -1.0 and $1.0 \mathrm{~K}$. Individual differences depend on actual weather conditions that specify the heat and momentum fluxes through the sea surface. During single diurnal cycles, $\Delta \mathrm{T}$ can vary by more than $1.0 \mathrm{~K}$. This fluctuation is able to hide variations of bulk SST when the sea surface is observed radiometrically. Only horizontal SST gradients that exceed $\Delta \mathrm{T}$ lead to a high coherence between bulk and skin temperatures. Nighttime $\Delta \mathrm{T}$ can be predicted with a knowledge of the standard meteorological measurements to an accuracy of $0.11 \mathrm{~K}$. The parameterization of the daytime $\Delta \mathrm{T}$ requires additional information on the radiative fluxes and can be as accurate as $0.17 \mathrm{~K}$. A day/night stratification of $\Delta \mathrm{T}$ shows significantly different distributions. Mean values of $\Delta \mathrm{T}$ are $\mathbf{0 . 3 0}$ $\mathrm{K}$ at night and $0.11 \mathrm{~K}$ during the day. Strongest skin cooling occurs during night under clear skies, a preferred condition for infrared remote sensing of the sea surface. The implications for SST retrievals from satellite data are most important when observing diumal warmings of the surface and when calibrating SST retrieval techniques with in situ buoy measurements. For the latter we recommend nighttime comparisons to avoid the diurnal thermocline and to include meteorological variables in a prediction model for $\Delta \mathrm{T}$ which should give the best "match-up" between satellite-derived skin temperatures and bulk temperatures measured from buoys. At night, SST retrievals can be carried out with the aid of the $3.7 \mu \mathrm{m}$ channel for cloud detection and filtering. Another type of calibration could be achieved by comparing remotely sensed SST's with in situ skin measurements; however, this requires a more sophisticated in situ experimental setup which is not practical for operational use.

Acknowledgments. We would like to acknowledge the assistance of the crew of the R/V Meteor in the collection of the data. We are also grateful to the staff of the Institut fuer Meereskunde, Kiel, Germany for help in setting up the data collection system. This study was supported by the Research Ministry of the Federal Republic of Germany (BMFT), the German Science Foundation (DFG), the European Communities, and by the Ocean Processes Branch of the U.S. National Aeronautics and Space Administration (NASA). This financial support is gratefully acknowledged.

\section{REFERENCES}

Bruch, H., Die vertikale Verteilung von Windgeschwindigkeit und Temperatur in der untersten Atmosph. are. Veroeff. Inst. fuer Meereskd. Berlin, Neue Folge, A38, 1940.

Clauss, E., H. Hinzpeter, J. Mueller-Glewe, Messungen der Temperaturstruktur im Wasser an der Grenzflache OzeanAtmosphare, Meteor Forschungsergeb., Reihe B, 5, 90-94, 1970.
Comillon, P., L. Stramma, The distribution of diumal sea surface warming events in the westem Sargasso Sea, J. Geophys. Res., 90, 11811-11815, 1985.

Downing, H. D., and D. Williams, Optical constants of water in the infrared, J. Geophys. Res., 80, 1656-1667, 1975.

Ewing, G., and E. D. McAlister, On the thermal boundary layer of the ocean, Science, 131, 1374-1376, 1960.

Friedmann, D., Infrared characteristics of ocean water (1.5 - 15 Hm), Appl. Opt., 8, 2073-2078, 1969.

Gould, J. W., The Northeast Atlantic Ocean, in Eddies in Marine Science, edited by A. R. Robinson, pp. 145-156, SpringerVerlag, New York, 1983.

Grassl, H., The dependence of the measured cool skin of the ocean on wind stress and total heat flux, Boundary Layer Meteorol., 10, 465-474, 1976.

Grassl, H., Gemessene Strahlungs- und Warmeflusse uber dem tropischen Ozean, Meteor Forschungsergeb., Reihe B, 12, 42 $50,1977$.

Grassl, H., and H. Hinzpeter, The cool skin of the ocean, GATE Rep., 14, 1, pp. 229-236, WMO/ICSU, Geneva, 1975.

Hasse, L., The sea surface temperature deviation and the heat flow at the sea-air interface, Boundary Layer Meteorol., I, 368-379, 1971.

Hinzpeter, H., Der Tagesgang der Wasseroberflachentemperanur in der Nahe des Aquators, Meteor Forschungsergeb., Reihe B, $1,41-44,1967$.

Hinzpeter, H., Tagesperiodische Anderungen des oberflachennahen Temperaturfeldes uber dem Meer als Folge von Strahlungsquellen und -senken, Kiel. Meeresforsch., 24, 1-13, 1968.

Katsaros, K. B., The sea surface temperature deviation at very low wind speeds; is there a limit?, Tellus, 29, 229-239, 1977.

McClain, E. P., Multiple atmospheric window techniques for satellite derived sea surface temperatures, in Oceanography From Space, edited by J.F.R. Gower, pp. 73-85, Plenum, New York, 1981.

McClain, E.P., Global sea surface temperatures and cloud clearing for aerosol optical depth estimates, Int. J. Remote Sens., 10, 763-769, 1989.

McClain, E. P., W. G. Pichel, C. C. Walton, Z. Ahmad, and J. Sutton, Multi-channel improvements to satellite-derived global sea surface temperatures, Adv. Space Res., 2, 43-47, 1983.

McClain, E. P., W. G. Pichel, and C. C. Walton, Comparative performance of AVHRR-based multichannel sea surface temperatures, J. Geophys. Res., 90, 11587-11601, 1985.

Payne, R. E., Albedo of the sea surface, J. Atmos. Sci., 29, 959 970, 1972.

Price, J.F., R.A. Weller, C.M. Bowers, and M.G. Briscoe, Diurnal response of sea surface temperature observed at the long-term upper ocean study $\left(34^{\circ} \mathrm{N}, 70^{\circ} \mathrm{W}\right)$ in the Sargasso Sea, $J$. Geophys. Res., 92, 14, 480-14, 490, 1987.

Robinson, I. S., Satellite Oceanography, 455 pp., Ellis Horwood, Chichester, England, 1985.

Robinson, I. S., N. C. Wells, and H. Charnock, The sea surface thermal boundary layer and its relevance to the measurements of sea surface temperature by airbome and spaceborne radiometers, Int. J. Remote Sens., 5, 19-45, 1984.

Saunders, P., The temperature at the ocean-air interface, J. Atmos. Sci., 24, 269-273, 1967.

Schluessel, P., H.-Y. Shin, W. J. Emery, and H. Grassl, Comparison of satellite derived sea surface temperatures with 
in-situ skin measurements, $J$. Geophys. Res., 92, 2859-2874, 1987.

Smith, S. D., Coefficients for sea surface wind stress, heat flux, and wind profiles as a function of wind speed and temperature, J. Geophys. Res., 93, 15467-15472, 1988.

Woodcock, A. H., Surface cooling and streaming in shallow fresh and salt waters, J.Mar. Res., 4, 153-161, 1941.

W. J. Emery, Colorado Center for Astrodynamics Research, Campus Box 431, University of Colorado, Boulder, CO, 80309.
H. Grassl, Max-Planck-Institut fuer Meteorologie, Bundesstrasse 55, 2000 Hamburg, F R G.

T. Mammen, Institut fuer Meereskunde, Duesternbrooker Weg $20,2300 \mathrm{Kiel}$, F R G.

P. Schluessel, Institut fuer Meteorologie, University of Hamburg, Bundesstrasse 55, 2000 Hamburg, F R G.

(Received October 11, 1989; revised February 23, 1990; accepted February 23, 1990.) 